\title{
UNSURPRISING SHOCKS: \\ Information, Premia, And the Monetary TRANSMISSION 放
}

\author{
Silvia Miranda-Agrippino* \\ Bank of England and CFM
}

First version: June 2015 - This version: August 8, 2017

\begin{abstract}
This article studies the information content of monetary surprises, i.e. the reactions of financial markets to monetary policy announcements. We find that monetary surprises are predictable by past information, and can incorporate anticipatory effects. Surprises are decomposed into monetary policy shocks, forecast updates, and time-varying risk premia, all of which can change following the announcements. Hence, their use as identification devices is not warranted, and can have strong qualitative and quantitative implications for the estimated responses of variables to the shocks. We develop new measures for monetary policy shocks, independent of central banks' forecasts and unpredictable by past information.
\end{abstract}

Keywords: Monetary Surprises; Identification with External Instruments; Monetary Policy; Expectations; Information Asymmetries; Event Study; Proxy SVAR.

JEL Classification: E52, E44, G14, C36

\footnotetext{
${ }^{*}$ Contact: Monetary Analysis, Bank of England, Threadneedle Street, London EC2R 8AH, United Kingdom.

E-mail: silvia.miranda-agrippino@bankofengland.co.uk Web: www.silviamirandaagrippino.com

is I am indebted to Raffaella Giacomini, Alejandro Justiniano, Ricardo Reis and Giovanni Ricco for many insightful discussions and for taking time to comment on earlier versions of this paper. I am grateful to Refet Gürkaynak for graciously sharing the updated daily US monetary surprises. I thank Francisco Gomes, Iryna Kaminska, Roland Meeks, Andrew Meldrum, Lubos Pastor, Michele Piffer, Valerie Ramey, Hélène Rey, Matt Roberts-Sklar, Paolo Surico, colleagues at the Macro-Financial Analysis Division of the Bank of England, seminar and conference participants at the Bank of England, London Business School, the University of Bonn, the University of Surrey, the Graduate Institute in Geneva, the Norges Bank, the 2016 RES annual meeting, the 2nd IAAE and 24th CEPR ESSIM conferences, the 2017 AEA Winter Meeting for useful suggestions. The views expressed in this paper are those of the author and should not be taken to reflect those of the Bank of England and any of its committees. This paper was previously circulated with the title "Unsurprising Shocks: Measuring Responses to Monetary Announcements using High-Frequency Data."

Online Appendix available at www.silviamirandaagrippino.com/s/MA2016_UnsurprisingShocks_OnlineAppendix.pdf
} 


\section{Introduction}

Recent advances in empirical monetary economics have advocated the use of market-based monetary surprises to achieve identification of the effects of monetary policy shocks. ${ }^{1}$ Monetary surprises are typically computed as the price updates of interest rates-linked securities that follow central banks' policy announcements. The argument in favor of their use is that, to the extent that these prices embed expectations about future policy rates, if the surprises are computed within sufficiently narrow windows around the announcements, they can then be thought of as a measure (with error) of the underlying monetary policy shocks.

Two crucial assumptions make market-based surprises the ideal candidate for the job: (i) markets efficiently incorporate all available information, and it takes longer than the measurement window for the monetary policy shock to modify the risk premium in these contracts, and ( $i i)$ the set of economic forecasts on the basis of which central banks' decisions are taken, and those of market participants coincide, leading to the equivalence between price updates and monetary policy shocks. These assumptions make it possible to first map all price changes into revisions in market-implied expectations about the policy rate and, second, to effectively interpret these announcement-triggered revisions as the monetary policy shock, up to scale and a random measurement error.

This paper produces evidence that challenges both these assumptions and argues that under general conditions, and independent from the length of the measurement window, monetary surprises capture more than just the shocks. Because private sector forecasts are not bound to be, and are generally not equal to central banks' forecasts, what markets label as unexpected may or may not be unanticipated by the central bank. That is, it may or may not be part of the systematic response to current or expected macroeconomic conditions that make up the reaction function of the monetary authority. ${ }^{2}$ Hence, monetary surprises can incorporate anticipatory effects if market participants are not able to correctly account for the systematic component of policy when they are

\footnotetext{
${ }^{1}$ In the paper we use the terms 'market-based monetary policy surprises', 'monetary surprises', and 'market surprises' interchangeably.

${ }^{2} \mathrm{We}$ use 'expected'/'unexpected' to refer to private-sector/market forecasts, and 'anticipated'/'unanticipated' for central banks forecasts. An event that is anticipated and unexpected is in the information set of the central bank but not in that of the public (e.g. news about future inflation).
} 
surprised by a policy decision. If the two sets of forecasts differ, the monetary surprises cannot be thought of as being exogenous, or assumed to be isolating the correct signal.

Depending on whether market participants see the interest rate move as the result of a monetary policy shock, or as part of the systematic reaction of policy to the economic outlook, their economic forecasts, the expected future path of policy, and the risk compensation they demand, will change in opposite directions, inevitably altering the signal in the monetary surprises. This can induce important distortions in the estimated responses of variables to the shocks when surprises are used as external instruments for identification. A contractionary monetary policy shock that materializes as an increase in the policy rate depresses output and prices. In such a scenario, forecasts are likely to be revised downward. However, an increase in the policy rate may just as well be a signal that the central bank is anticipating buoyant times, along with inflationary pressures. If this is the case, forecasts will be revised upward instead. If investors demand a risk compensation that is a function of the expected macroeconomic outlook, then this is also likely to change following the forecast revision triggered by the announcement.

Hence, the surprises will in general be a function of the shocks and of the forecast update triggered by the implicit revelation of central banks' forecasts that happens at the time of the announcements (see also Barakchian and Crowe, 2013; Nakamura and Steinsson, 2017; Melosi, 2017). Using a simple New-Keynesian framework, we show that the dependence of monetary surprises on forecasts of macroeconomic fundamentals makes them dependent on past information as well. Consistent with this hypothesis, we document a new stylized fact. Namely, other than being correlated with central banks' forecasts, as also noted in Gertler and Karadi (2015) and Ramey (2016), high-frequency monetary surprises are predictable by public data whose release predates the announcements. This empirical regularity holds both across financial instruments and countries. The predictability of market surprises using past information can be given a risk premium interpretation (see e.g. Fama and French, 1989; Fama, 1990, 2013). Because monetary surprises are effectively returns realized over tiny time intervals, the predictability can be interpreted as indicating the presence of a time-varying risk premium - induced by the dependence on macroeconomic forecasts -, that changes at the time of the announcement because of the partial resolution of uncertainty about the future path of policy, and 
of macroeconomic conditions more generally, that is triggered by the policy decision. ${ }^{3}$ By the same token, and consistent with our model's predictions, we show that once the anticipatory effects are accounted for, and forecasts are aligned, past data become uninformative.

We develop a new set of measures for monetary policy shocks by projecting market surprises on central banks' forecasts and forecasts revisions of the key variables that are likely to enter the central bank's reaction function, and use the residuals to identify the shocks. The composition of the conditioning set is similar to the one in Romer and Romer (2004). The resulting instruments, orthogonal to central banks' forecasts by construction, are shown to be uncorrelated with summary measures of the information available to the public. Lagged factors summarizing the pre-existing macroeconomic and financial environment, and that were significant predictors of the original surprises, are uncorrelated with the orthogonal ones. The orthogonal surprises proposed in this paper are thus better candidates for the task of capturing only the unanticipated monetary policy shocks.

The importance of purging anticipatory effects from monetary surprises lies at the very core of the identification of the effects of monetary policy shocks (see e.g. Sims, 1992). If the central bank is raising the policy rate because it anticipates higher inflation or growth above potential, failing to account for the anticipation will result in misleadingly attributing the cause of higher growth and inflation to the higher interest rate. Because of the confounding role played by such anticipatory effects, monetary policy shocks 'identified' using market surprises can induce responses of key variables that carry strongly counterintuitive signs. In particular, significant real activity puzzles can emerge. ${ }^{4}$ Conditional on the same empirical model, and hence on the same implied dynamics, we show that using either the original or the orthogonal surprises as identification devices can imply profoundly different responses of variables to the shocks. Generally, using the original

\footnotetext{
${ }^{3}$ Corroborating evidence of global investors demanding a premium to bear risk associated to central banks' decisions is in e.g. Lucca and Moench (2015); Vissing-Jorgensen, Morse and Cieslak (2015). Similarly, Cieslak (2016) produces evidence of predictability of realized bond excess returns that is induced by information asymmetries.

${ }^{4}$ Campbell, Evans, Fisher and Justiniano (2012); Nakamura and Steinsson (2017); Campbell, Fisher, Justiniano and Melosi (2016) document similar evidence using survey-based forecasts. In particular, these papers find that positive market surprises are associated with improved forecasts for both output and unemployment.
} 
surprises delivers at best attenuated responses, due to the anticipatory effects inducing responses whose sign is opposite to that implied by standard monetary policy shocks. Intuitively, the correction to the surprises proposed in this paper eliminates the distortions in the estimated structural impulse response functions that arise from omitting information which both the VAR innovations and the original market surprises depend on.

This paper extends the work of Barakchian and Crowe (2013), who are the first to discuss the assumption of equivalence between private sector forecasts and central banks' forecasts in the identification of monetary policy shocks using daily surprises in futures markets. Early uses of financial market instruments to extract expectations about the path of short-term interest rates date back at least to the early nineties (see e.g. Cook and Hahn, 1989; Svensson, 1994; Soderlind and Svensson, 1997; Kuttner, 2001; Cochrane and Piazzesi, 2002; Piazzesi, 2002). Rudebusch (1998) was the first to suggest the inclusion of futures on interest rates in monetary VARs to overcome the potentially misspecified reaction function implicitly estimated in these models. Estimates of the unexpected component of policy have become more sophisticated with the availability of high-frequency financial data (Sack, 2004; Gürkaynak, 2005; Gürkaynak, Sack and Swanson, 2005). Gertler and Karadi (2015) are the first to use monetary surprises as external instruments for the monetary policy shock in a Proxy Structural VAR (Stock and Watson, 2012; Mertens and Ravn, 2013). The availability of potentially clean measures of monetary shocks has since spurred a number of diverse applications whereby monetary surprises extracted from financial market instruments have been used to quantify the effects of both conventional and unconventional monetary policy shocks. To mention just a few, Hanson and Stein (2015) find large responses of long-term real rates to monetary policy shocks and explore the transmission of monetary policy to real term premia using intraday changes in the two-year nominal yield. Nakamura and Steinsson (2017) employ a 'policy news shock' - defined as the first principal component of monetary surprises calculated using a selection of interest rate futures - to show that long-term nominal and real rates respond roughly one to one to monetary policy shocks. Similarly, Swanson (2015) identifies 'forward guidance' and 'large-scale asset purchases' dimensions of monetary policy shocks at the zero lower bound using principal components of a selection of 
futures on short-term interest rates and long-term government bond yields, and employs them to study the effects of unconventional monetary policy on asset prices. Glick and Leduc (2015) use monetary surprises in federal funds futures and a collection of Treasury rate futures at longer maturities to study the effects of conventional and unconventional monetary policy on the dollar. Finally, Rogers, Scotti and Wright (2014) measure the pass-through of unconventional monetary policy implemented by four different central banks on asset prices by using monetary surprises calculated from long-term government bond yields in each of the monetary areas considered. Miranda-Agrippino and Ricco (2016) study the transmission of monetary policy shocks in the presence of informational frictions, and discuss the challenges to identification posed by the presence of information asymmetries and by the slow and imperfect absorption of information by both economic agents and the central bank. Monetary surprises are there used as a proxy for the aggregate revisions in expectations to construct an identification strategy that is robust to non-nested information sets of the central bank and private agents.

\section{The Information Content of Monetary Surprises}

Consider an economy in which the behavior of households and firms is described by the following two equations: ${ }^{5}$

$$
\begin{aligned}
& x_{t}=x_{t+1 \mid t}-\sigma\left(i_{t}-\pi_{t+1 \mid t}-r_{t}^{n}\right), \\
& \pi_{t}=\beta \pi_{t+1 \mid t}+\kappa x_{t} .
\end{aligned}
$$

Eq. (1) is obtained from the linearized Euler equation and expresses the current output gap $x_{t}$ as a function of the expected output gap $x_{t+1 \mid t} \equiv \mathbb{E}_{t}\left[x_{t+1}\right]$ and of future expected deviations of the real interest rate from its natural rate $r_{t}^{n}$. Within this simple model, the natural rates of interest and of output are both functions of exogenous shocks to technology and preferences. One could think of richer frameworks where the natural interest rate is also a function of other shocks, such as to households borrowing constraints,

\footnotetext{
${ }^{5}$ The model we refer to is a workhorse three-equation New-Keynesian model (see Woodford, 2003; Galí, 2008, for textbook treatment).
} 
or to the financial sector, without altering the essence of the argument discussed below. The parameter $\sigma$ denotes the intertemporal elasticity of substitution. The behavior of inflation is regulated by the Phillips curve - Eq. (2), where $\kappa$ regulates the size of the response of inflation to changes in the output gap. The central bank sets the interest rate according to the following simple rule

$$
r_{t} \equiv i_{t}-\pi_{t+1 \mid t}=r_{t}^{n}+e_{t}
$$

therefore, the monetary authority chooses the real interest rate in such a way to track the natural rate of interest, with deviations from the rule denoted by $e_{t} .{ }^{6}$

Solving Eqs. (1) and (2) forward one obtains

$$
\begin{aligned}
& x_{t}=-\sigma \sum_{j=0}^{\infty}\left(r_{t+j \mid t}-r_{t+j \mid t}^{n}\right), \\
& \pi_{t}=\kappa \sum_{j=0}^{\infty} \beta^{j} x_{t+j \mid t} .
\end{aligned}
$$

Absent any monetary policy shock - i.e. if $e_{t}=0$, the real interest rate equals the natural rate, and both the output gap and expected inflation are equal to zero. Conversely, a monetary policy tightening (loosening) will result in the real rate being larger (smaller) than the natural rate, a contraction (expansion) in economic activity, and a decline (rise) in inflation.

Within this framework, agents form expectations by projecting on current realizations of the shocks, of which current macroeconomic fundamentals are a contemporaneous function. Let the policy announcement be scheduled in the interval $(t-\Delta t, t)$. The expected level of the nominal interest rate just before the announcement can be expressed as

$$
i_{t \mid t-\Delta t}=r_{t \mid t-\Delta t}^{n}=\Theta \Omega_{t}
$$

where we assume that agents know that the central bank will revert to its rule following any shock, from which it follows that $\pi_{t+1 \mid t-\Delta t}=0 . \Omega_{t}$ is the vector collecting the current

\footnotetext{
${ }^{6}$ For the sake of building the intuition, we choose to adopt the simple framework in Andrade and Ferroni (2016), however, the rule can be extended to include a Taylor principle as in Nakamura and Steinsson (2017).
} 
realizations of macroeconomic fundamentals, and $\Theta$ is a non-linear function of primitive model parameters and denotes the coefficients of the projection. In reality, however, the current value of macroeconomic fundamentals is not known in real time and must be estimated. Eq. (6) thus transforms into

$$
r_{t \mid t-\Delta t}^{n}=\Theta \widehat{\Omega}_{t \mid t}
$$

where $\widehat{\Omega}_{t \mid t}$ denotes the forecast/nowcast of $\Omega_{t}$. It is assumed that in the time interval $\Delta t$ no news relative to macro fundamentals are released to the public, that is, the monetary announcement is the only event in the measurement window. In the absence of competing data releases, and conditional on the forecasting model being unchanged, $\widehat{\Omega}_{t \mid t}=\widehat{\Omega}_{t \mid t-\Delta t}$.

Consider the price of a futures contract on the nominal interest rate that pays the rate prevailing at some future date $t+h$

$$
p_{t}^{(h)}=\mathbb{E}_{t}\left[i_{t+h}\right]+\zeta_{t}^{(h)},
$$

where $\zeta_{t}^{(h)}$ denotes the risk premium that may be present in the contract. Eq. expresses the price of the futures contract as a function of the expected future nominal rate $i_{t}$ plus a risk compensation that investors require to hold such a contract to maturity.

Using Eqs. (7) and (8) one can express the price just before the announcement as

$$
p_{t-\Delta t}^{(h)}=i_{t+h \mid t-\Delta t}\left(\widehat{\Omega}_{t \mid t}\right)+\zeta^{(h)}\left(\widehat{\Omega}_{t \mid t}\right),
$$

where the dependence on the economic forecasts is made explicit. In Eq. (9) the timevariation in the risk premium is derived from the dependence of the premium on either realized or expected macroeconomic fundamentals.

Without loss of generality, consider now the futures contract expiring at the end of the current month, i.e. the front contract. Assume that market participants have access to the same pool of public data as the central bank, and that they know the reaction function of monetary authority. We also assume that the reaction function does not vary. ${ }^{7}$

\footnotetext{
${ }^{7}$ The scenario in which the central bank's reaction function evolves over time and agents gradually
} 
The price that investors attach to such a contract just before the relevant monetary policy announcement is equal to

$$
p_{t-\Delta t}=i_{t \mid t-\Delta t}^{\mathrm{M}}+\zeta\left(\widehat{\Omega}_{t \mid t}^{\mathrm{M}}\right)=f\left(\widehat{\Omega}_{t \mid t}^{\mathrm{M}}\right)+\zeta\left(\widehat{\Omega}_{t \mid t}^{\mathrm{M}}\right)
$$

$i_{t \mid t-\Delta t}^{\mathrm{M}}$ is the expected policy decision. Given market participants' forecasts about $\Omega_{t}$, and the central bank's reaction function $f$, what investors expect the interest rate to be after the announcement is equal to $f\left(\widehat{\Omega}_{t \mid t}^{\mathrm{M}}\right)$. Conditional on the same set of forecasts, the risk premium equals $\zeta\left(\widehat{\Omega}_{t \mid t}^{\mathrm{M}}\right)$.

After the policy decision is revealed, the futures price is updated accordingly

$$
p_{t}=\underbrace{f\left(\widehat{\Omega}_{t \mid t}^{\mathrm{CB}}\right)+e_{t}}_{i_{t}}+\zeta\left(\widehat{\Omega}_{t \mid t}^{\mathrm{CB}}\right) .
$$

The new policy rate is a function of the central bank's forecast $\widehat{\Omega}_{t \mid t}^{\mathrm{CB}}$ and of a possibly non-zero shock $e_{t}$. Consequently, the newly demanded risk premium is also revised. The risk compensation is associated to the uncertainty about the future path of policy, and of macroeconomic conditions more generally; if the forecast for $\Omega_{t}$ changes, the risk premium that investors demand will reflect that change.

Market surprises are computed as the price update that follows the communication of the interest rate decision, that is, $m p s_{t} \equiv p_{t}-p_{t-\Delta t} \cdot{ }^{8}$ All else equal, the fact that the economic forecasts of the central bank may not coincide with those of the private sector makes the surprises a contemporaneous function of more than just the monetary policy shocks. In fact, for the price update to be mapped into the monetary policy shock it has to be the case that $\widehat{\Omega}_{t \mid t}^{\mathrm{CB}}=\widehat{\Omega}_{t \mid t}^{\mathrm{M}}$ (see also Barakchian and Crowe, 2013); in general, the monetary surprise will otherwise be equal to

$$
m p s_{t} \equiv p_{t}-p_{t-\Delta t}=f\left(\widehat{\Omega}_{t \mid t}^{\mathrm{CB}}-\widehat{\Omega}_{t \mid t}^{\mathrm{M}}\right)+\zeta\left(\widehat{\Omega}_{t \mid t}^{\mathrm{CB}}-\widehat{\Omega}_{t \mid t}^{\mathrm{M}}\right)+e_{t}
$$

learn about it is to a large extent observationally equivalent to the one discussed here. While trying to disentangle the two cases goes beyond the scope of the present analysis, we note here that the increased transparency in central banks' communication about their decisions, intentions and preferences might have made our assumptions less untenable. We leave a proper investigation in this sense for future research.

${ }^{8}$ Specific details on futures on interest rates and their use in the construction of monetary surprises are in Appendix A. 
Eq. (11) establishes that it suffices that private forecasts do not align with those of the monetary authority for the surprise to be an invalid tool for identification. This assumption has been challenged in a number of papers, starting with the seminal contribution of Romer and Romer (2000). Note that for Eq. (11) to hold it suffices that the central bank and market participants only differ in the forecasting model they choose to employ, everything else, including the reaction function $f(\cdot)$, being equally known to both.

Monetary surprises can therefore incorporate anticipatory effects, with important consequences for the correct identification of the responses of variables to the shocks. The misalignment of $\widehat{\Omega}_{t \mid t}^{\mathrm{CB}}$ and $\widehat{\Omega}_{t \mid t}^{\mathrm{M}}$ leads agents to update their own forecasts in directions which are incompatible with the responses to a monetary policy shock predicted by standard macroeconomic theory. Using Blue Chip forecasts, Nakamura and Steinsson (2017) show that increases in interest rates are associated with significant upward revision of growth forecasts, up to about a year into the future. Similar evidence is reported in Campbell, Evans, Fisher and Justiniano (2012) and Campbell, Fisher, Justiniano and Melosi (2016). Campbell et al. (2012) also find that Blue Chip forecasts of unemployment are revised downward following an increase in the policy rate. Similarly, forecasters expect higher inflation. Campbell et al. (2016) attribute these puzzling responses to the fact that the central bank and the public are not equally well informed about macroeconomic fundamentals, that is, their forecasts differ: policy decisions transfer knowledge about the central bank's forecasts and this triggers private sector forecasts revisions of the 'wrong' sign.

Eq. (11) implies that just like professional forecasters, market participants are subject to the same type of information asymmetries. And that following an announcement they may revise prices because of a monetary policy shock, of a forecast update, or a combination of the two. Removing the confounding factors is thus critical for the correct identification of the shocks and their effects. Figure I illustrates the point.

\section{[ INSERT Figure I ABOUt HeRE ]}

In Section 5, motivated by Eq. (11), we construct orthogonal surprises by projecting 
market surprises $\left(p_{t}-p_{t-\Delta t}\right)$ on the lagged policy rate and on central bank's forecasts, and use the residuals to identify the monetary policy shocks. The fitted part of this regression embeds the component of market surprises that instead captures the forecast update (and consequential revision in the risk premium). The impulse response functions (IRFs) in Figure I separate the effects that are due to the monetary policy shocks (residuals of Eq. (16), solid lines), from those induced by the forecast update that happens at the time of the policy announcements (fitted part of Eq. (16), dashed lines). Conditional on the same VAR, and hence on the same set of residuals and implied dynamics, the two sets of responses are obtained by using each of the two components in turn as an external instrument. ${ }^{9}$ Empirically, the contemporaneous transmission coefficients that determine the impact responses are obtained as a function of the projection of the reduced-form VAR innovations on each of the two components of the monetary surprises (see next section for details). The responses are normalized such that both components raise the policy rate by $1 \%$ on impact. The two components of the monetary surprises are orthogonal to one another, hence, the IRFs recovered by the market surprises will be generally attenuated due to the components triggering responses of the main economic variables that carry opposite signs. Depending on which of the two prevails, the overall responses to a shock 'identified' using market surprises may thus lead to responses to a monetary policy shock that are strongly counterintuitive, such as those implied by the components in Figure I.

In Section 3 we explore the technical reasons behind the puzzling responses that may arise when using monetary surprises to identify the shocks. The testable implications of Eq. (11) are in Section 4.

\section{Instruments for Monetary Policy Shocks}

Let $y_{t}$ be an $n$-dimensional vector of observables whose responses to the structural shocks in $e_{t}$ are given by

$$
y_{t}=[A(L)]^{-1} u_{t}=\mathcal{C}(L) \mathbf{B} e_{t},
$$

\footnotetext{
${ }^{9} \mathrm{VAR}(12)$ estimated in levels over the period 1969:2014. Other variables included are an index of commodity prices and the one year rate as the policy variable. See Section 5 for further details.
} 
where $\mathcal{C}(L) \mathbf{B}$ are the structural IRFs. $u_{t}$ are the reduced-form innovations, with $u_{t}=\mathbf{B} e_{t}$. B collects the contemporaneous transmission coefficients. ${ }^{10}$

Suppose one is interested in calculating the responses of $y_{t}$ to a particular shock in $e_{t}$, call it the monetary policy shock, and denote it by $e_{t}^{\bullet}$. The identification of the relevant column $\mathbf{b}^{\bullet}$ of $\mathbf{B}$ is achieved via a set of variables $z_{t}$, not in $y_{t}$, such that

$$
\mathbb{E}\left[e_{t}^{\bullet} z_{t}^{\prime}\right]=\phi^{\prime}, \quad \mathbb{E}\left[e_{t}^{\circ} z_{t}^{\prime}\right]=0,
$$

and $\phi$ is non-singular. $e_{t}^{\circ}$ denotes structural shocks other than the one of interest. If one or more variables $z_{t}$ can be found such that these conditions are satisfied, then $\mathbf{b}^{\bullet}$ can be identified up to scale and sign using only moments of observables. ${ }^{11}$ Conditions in Eq. (13) are the key identifying assumptions, and resemble the standard conditions for external instruments' validity. Whilst in general there is no formal way to verify that the conditions in Eq. (13) hold, the identification relies on a number of other requirements that only involve observables and are thus fully testable. ${ }^{12}$

In particular for our purpose, suppose $\mathbf{b}^{\bullet}$ is estimated using the two-step procedure whereby the reduced-form innovations $u_{t}$ are projected onto the instruments $z_{t}$. Let $\mathrm{X}_{t}$ be a vector of variables omitted from the VAR but such that

$$
\mathbb{E}\left[z_{t} \mathrm{X}_{t-1}^{\prime}\right] \neq 0, \quad \mathbb{E}\left[u_{t} \mathrm{X}_{t-1}^{\prime}\right] \neq 0
$$

In this case, the two-step procedure is misspecified and the identification compromised, as Eq. (14) implies potentially severely biased estimates of the parameters in $\mathbf{b}^{\bullet}$. The discussion in the next section, and related to the predictability of the monetary surprises, will technically fall within this context.

An equivalent way of addressing the identification of $\mathbf{b}^{\bullet}$ is to cast the problem in a measurement error framework where the structural shock of interest is treated as an un-

\footnotetext{
${ }^{10} A(L) \equiv\left[\mathbb{I}_{n}-A_{1} L-\ldots-A_{p} L^{p}\right]$, where $A_{i}, i=1, \ldots p$, are conformable matrices of autoregressive coefficients. The structural shocks are such that $\mathbb{E}\left[e_{t}\right]=0, \mathbb{E}\left[e_{t} e_{t}^{\prime}\right]=\mathbb{I}_{n}$ and $\mathbb{E}\left[e_{t} e_{\tau}^{\prime}\right]=0 \forall \tau \neq t$.

${ }^{11}$ See Stock and Watson (2012); Mertens and Ravn (2013); Montiel-Olea, Stock and Watson (2016).

${ }^{12}$ See Stock and Watson (2017) for a thorough description of the conditions under which external instrument methods produce valid inference on dynamic causal effects.
} 
observed regressor, and the external instrument is explicitly modelled as a proxy variable

$$
z_{t}=\Phi e_{t}^{\bullet}+\nu_{t}
$$

where $\nu_{t}$ is an i.i.d. measurement error and $\Phi$ is non-singular. In this case, all the relevant model parameters ( i.e. $A(L)$ and $\mathbf{B}$ ) are jointly estimated in an error-in-variable system where $z_{t}$ is effectively treated as a scaled version of the shock up to a random error. This procedure delivers consistent estimates of $\mathbf{b}^{\bullet}$ only under the additional assumption that the instrument is uncorrelated with the lagged endogenous variables included in the VAR. Furthermore, Eq. (15) implies that just like the shock itself, the instrument should not be forecastable given lagged information relative to own lags or lags of any other variable, regardless of whether it is included in $y_{t}$ or not. These conditions resemble the informational sufficiency requirement on the observables included in any structural VAR (see e.g. Forni and Gambetti, 2014), and call for the absence of any endogenous variation in the dynamics of $z_{t}$. The intuition here is that if this is not the case, then there is no reason why one would not want to include $z_{t}$ in the set of endogenous observables $y_{t}$ and let it act as an instrument for itself (see e.g. Bagliano and Favero, 1999; Barakchian and Crowe, 2013). In fact, an equivalent way of estimating the transmission coefficients is to include $z_{t}$ in the set of endogenous observables and identify the monetary policy shock by ordering it first in a standard Cholesky triangularization. ${ }^{13}$

\section{Predictable Surprises}

In this section we take Eq. (11) to the data, and test the dependence of monetary surprises on both central banks' forecasts and past information. In the language of Section 3, we test for $\mathbb{E}\left[z_{t} \mathrm{X}_{t-1}^{\prime}\right]=0$, where $\mathrm{X}_{t-1}$ is a collection of variables likely to be in the information set of either or both the central bank and market participants at the time of the monetary announcement. ${ }^{14}$ In what follows, US monetary surprises are those in Gürkaynak, Sack

\footnotetext{
${ }^{13}$ Empirically, the successful identification of $\mathbf{b}^{\bullet}$ is ultimately a question of both specifying the VAR correctly, and singling out a reasonably valid instrument. If doubts arise about the effective exogeneity of the chosen instrument, one way to mitigate the distortions on the estimated contemporaneous transmission coefficients is to enrich the information set of the VAR to produce 'cleaner' innovations.

${ }^{14}$ We abstract from concerns related to the design of trading strategies and out-of-sample predictability of monetary surprises that, while relevant in their own right, go beyond the scope of the present analysis.
} 
and Swanson (2005), extended until 2012. Namely, the surprises are extracted from the first (MP1) and fourth (FF4) federal funds futures, and from the second (ED2), third (ED3) and fourth (ED4) Eurodollar futures. UK surprises are novel, and constructed using the next expiring short sterling futures (Ss1). The sample for the construction starts in June 1997, which coincides with the first decision meeting after the Bank of England's Monetary Policy Committee was granted operational independence for setting monetary policy. To assess the behavior of market participants around policy-relevant events other than the rate announcements, UK monetary surprises are also computed on extended sets of dates that add to the rate decision the release of the minutes of the MPC meetings (SS1M), and of the quarterly Inflation Report (SS1MIR). Because the latter events are often contemporaneous to major economic data releases that are also market movers, we control for all data releases which are scheduled within the measurement window. The length of the measurement window $(\Delta t)$ is equal to 30 minutes, with the exception of the broad UK-based surprises that also cover the release of the minutes and of the Inflation Report (i.e. the SS1MIR case). When the IR is the relevant policy event, we set $\Delta t$ equal to 90 minutes to account for the duration of the IR press conference. The reader is referred to Appendix A for a thorough description of the surprises and their time series properties, and of the financial instruments used for their construction. ${ }^{15}$

In Table I, US monetary surprises are projected onto Greenbook forecast revisions between two consecutive meetings for output $(y)$, inflation $(\pi)$, and unemployment $(u)$. Forecast horizons considered are $h=0,1,2$, and expressed in quarters. Hence, $\Delta y_{t \mid t}^{G B}$ denotes the forecast revision for current-quarter output growth. All regressions include a constant and 4 lags of the dependent variable. The sample considered is 1990-2009.16 September 2001 is not included to address the concerns in in Campbell et al. (2012). Forecasts are aligned such that they correspond to the FOMC meeting the surprises refer to. For the months in which no FOMC meeting is scheduled the revision is set to zero. Greenbook forecast revisions are a function of the update in the information set of the

\footnotetext{
${ }^{15}$ Cesa-Bianchi, Thwaites and Vicondoa (2016) also use high-frequency data to construct proxies for monetary policy shocks in the UK; their proxies roughly correspond to the monetary surprise calculated around all policy events constructed here (SS1MIR) and further discussed in Appendix A.

${ }^{16}$ We stop in 2009 to avoid the discontinuity introduced by the Zero/Effective Lower Bound episodes. Monetary surprises also correlate with Greenbook level forecasts for output, inflation, and unemployment. Regressions are not reported for space considerations but are available on the Online Appendix.
} 
Federal Reserve that occurs between any two consecutive meetings. Results in the table confirm that central banks' forecasts are highly informative for all the monetary surprises considered, in support of the view that central bank's forecasts do enter the specification in Eq. (11). The correlation of high-frequency market surprises with central bank's forecasts is also noted in Gertler and Karadi (2015) and Ramey (2016).

\section{[ INSERT TABLE I ABOUT HERE ]}

In Section 2 we postulated that the dependence of monetary surprises on central banks' forecasts makes them dependent on past information as well. This was summarized by the premium component $\zeta\left(\widehat{\Omega}_{t \mid t}^{\mathrm{CB}}-\widehat{\Omega}_{t \mid t}^{\mathrm{M}}\right)$. We test this hypothesis in Table II. The top panel of Table II reports predictability results relative to a set of ten lagged macroeconomic and financial factors estimated from the 134 US monthly series assembled in McCracken and $\mathrm{Ng}$ (2015). ${ }^{17}$ The factors enter the specification with a month's lag. As before, all regressions include a constant and 4 lags of the dependent variable. Surprises are predictable by past information, summarized by the lagged macro-financial factors. One concern with regressing on these factors is that they are estimated on the last available vintage of data, that thus includes revisions that occurred after the surprise was measured. Moreover, due to the sometimes significant delay with which data are released, the information set from which the factors are extracted was not entirely visible at the time of the announcements, even if factors are lagged one month. To address this concern, we repeat the factor extraction only on the subset of the variable in McCracken and $\mathrm{Ng}$ (2015) that are not subject to revision, such as financial variables and surveys. These are the $f^{*}$ factors in the bottom panel of Table II. Results show that the dependence of monetary surprises on past information survives also when only data that were effectively available before the time of the announcement are considered. ${ }^{18}$

\footnotetext{
${ }^{17}$ Factors are obtained by estimating a Dynamic Factor Model (Forni et al., 2000; Stock and Watson, 2002) with VAR(1) dynamics and diagonal idiosyncratic variance. Maximum likelihood estimates of the factors, their variances and model parameters are obtained using the EM algorithm and Kalman filter for the DFM cast in state space form, and iterating until convergence. The algorithm is initialized with static principal components and least squares estimates for the state space parameters. Prior to estimation, all variables are opportunely transformed to achieve stationarity.

${ }^{18}$ Results on predictability survive for samples starting after 1994 and ending before the onset of the financial crisis of 2007-2008 (reported in the Online Appendix).
} 
Tables III and IV repeat the same exercise for the UK. We use Inflation Report (IR) forecasts to proxy for the central bank information as in Cloyne and Hürtgen (2016). As before, we set the forecast revisions equal to zero for the months in which no IR is scheduled. The macroeconomic and financial factors are extracted from a set of monthly UK variables selected to be a UK counterpart of the set in McCracken and Ng (2015). ${ }^{19}$ These enter the regressions with a month's lag. All regressions include a constant and four lags of the dependent variable. The sample is 2001:2009 to match that of the orthogonal surprises constructed in the next section. Results for the UK largely confirm what discussed for the US, although the evidence in this case is weaker due to the smaller number of observations available. Nevertheless, the same qualitative conclusions hold, and more importantly, the same type of confounding factors related to the forecasts updates are found. As discussed in the next section, and similar to the US case, the removal of the anticipation effects proxied by the central banks' forecasts (here IR) resolves the real activity puzzles otherwise emerging when using the original market surprises (i.e. the dependent variable in both Tables III and IV). ${ }^{20}$ Hence, we find evidence in support of the decomposition in Eq. (11), despite the weaker statistical significance of the regression coefficients reported in the tables.

[ INSERT TABLE III ABOUT HERE ]

\section{[ INSERT TABLE IV ABOUT HERE ]}

\footnotetext{
${ }^{19}$ The complete list of data and the transformations applied prior to the factor extraction are reported in the Online Appendix.

${ }^{20}$ Complementary evidence is reported in Figure A.III in Appendix A, where the SS1 and Ss1MIR series are plotted. As shown, expanding the set of policy events to include the minutes and the IR does not seem to alter the overall informational content of the ss1-based monthly surprise series.
} 


\section{Orthogonal Monetary Surprises and Shock Identi- fication}

Consistent with the intuition detailed in Section 2, the results collected in the previous section suggest that market surprises should not be used as external instruments for monetary policy shocks unconditionally. The mere fact of narrowing down the measurement window to a short time span surrounding the time of the announcement does not guarantee that the price updates are indeed only a function of the underlying monetary policy shocks. Confounding factors arising from the presence of anticipatory effects can in fact give rise to important distortions in the estimated IRFs, as discussed in Section 2. In Eq. (11), it is the misalignment between $\widehat{\Omega}_{t}^{\mathrm{CB}}$ and $\widehat{\Omega}_{t}^{\mathrm{M}}$ that causes the anticipatory effects to arise. We use this observation to construct orthogonal surprises for the identification of monetary policy shocks.

\subsection{Orthogonal Monetary Surprises}

We construct instruments for monetary policy shocks using the component of market surprises that is orthogonal to central banks' forecasts. Empirically, we project monthly monetary surprises onto a set containing the lagged interest rate and a set of forecasts and forecast revisions of the key variables that are likely to enter the central bank's reaction function. The composition of the conditioning set is motivated by the decomposition in Eq. (11), and similar to the one in Romer and Romer (2004). The orthogonal monetary policy surprises $\left(m p s_{t}^{\star}\right)$ are defined as the residuals of the following regression estimated at monthly frequency:

$$
m p s_{t}=\mu+\alpha i_{t-1}+\underbrace{\sum_{j=-1}^{3} \gamma_{j} \widehat{\Omega}_{t \mid q+j}^{\mathrm{CB}}}_{\text {level forecasts }}+\underbrace{\sum_{j=-1}^{2} \delta_{j}\left[\widehat{\Omega}_{t \mid q+j}^{\mathrm{CB}}-\widehat{\Omega}_{t-1 \mid q+j}^{\mathrm{CB}}\right]}_{\text {forecast revisions }}+m p s_{t}^{\star} .
$$

To proxy for the information included in the central bank's reaction function at the time of the announcement, we use staff forecasts produced ahead of policy meetings for output, inflation, and unemployment. Forecasts horizons considered are the previous and current quarter, and up to three quarters ahead. We include in the conditioning set both 
the level forecasts and forecast revisions between consecutive forecast dates. Depending on the release schedule of the variables of interest, these forecasts are substituted with actually released data whenever they become available. As in Romer and Romer (2004), we only include unemployment nowcasts due to the strong correlation between output growth and unemployment. We also include the lagged level of the target interest rate to control for state-dependent systematic market reactions. Lastly, if the futures contract is on an interest rate other than the overnight (e.g. LiBOR), we augment Eq. (16) with a correction term that takes into account the discrepancy between the two. ${ }^{21}$ The variables that enter the conditioning set are either unrevised or have a trackable revision history, meaning that the conditioning can be carefully done to ensure that the different information sets are properly aligned at all times.

In Section 2 we postulated that the misalignment between the two sets of forecasts was responsible for the dependence of market surprises on past information, hypothesis which we tested in Section 4. By the same token, Eq. (11) implies that once the forecast asymmetry is accounted for, past data should become uninformative. Consistent with this intuition, we find that the same set of macro-financial factors used in Section 4 are uncorrelated with the orthogonal surprises (see Table V), suggesting that the procedure in Eq. (16) is effective in delivering instruments for the monetary policy shocks that are orthogonal to the available information, and that also result from policy decisions that are not taken in response to either current or future economic developments. In this sense, the orthogonal surprises suggested here are better candidates for the task of capturing only the unexpected and unanticipated component of monetary policy decisions. The absence of correlation with past information that results from the orthogonalization in Eq. (16) also makes the use of orthogonal surprises less dependent on the composition of the information set in the preferred reduced-form monetary VAR. As discussed in Section 3 , the dependence of the instruments on past information (i.e. $\mathbb{E}\left[z_{t} \mathrm{X}_{t-1}^{\prime}\right] \neq 0$ ) can severely hinder the correct estimation of the contemporaneous transmission coefficients if the VAR innovations are also correlated with $\mathrm{X}_{t-1}$.

\footnotetext{
${ }^{21}$ In earlier drafts, the regression in Eq. (16) also included the change in the policy rate that market participants were reacting to. We removed that regressor due to potential endogeneity concerns. We note, however, that none of the results are sensitive to the inclusion of this variable. Older orthogonal surprises are available for download at: http://www.silviamirandaagrippino.com/research/.
} 
For the US, the conditioning set contains (a) Greenbook forecasts and forecast revisions for output and inflation for the previous and the current quarter and up to three quarters ahead, and of current unemployment; and (b) the lagged federal funds rate. We apply the decomposition in Eq. (16) to surprises extracted from the fourth federal funds futures. These contracts pay the average federal funds rate that is realized in the expiry month, and have a three-month maturity. Monthly surprises are constructed by assigning the daily surprise to the month in which the relevant FOMC announcement is scheduled. If more than one monthly meeting is present, the surprises are summed within the month. The original $(\mathrm{FF} 4)$ and orthogonal $\left(\mathrm{FF} 4^{\star}\right)$ monthly surprises extracted from the fourth federal funds futures are plotted in Figure II for the period 1990-2009. The upper time bound to the construction of the orthogonal surprises is partially constrained by the 5year publication lag of the Greenbook forecasts, and more generally motivated by the fed funds rate reaching the zero lower bound in 2009. The lower bound is constrained by the availability of daily surprises.

\section{[ INSERT FIGURE II ABOUT HERE ]}

\section{[ INSERT FIgURE III ABOUT HERE ]}

Measuring responses to a monetary policy shock in the UK using high-frequency futures data presents some difficulties, primarily related to the fact that no financial contract with a sufficiently long history is directly linked to Bank Rate. ${ }^{22}$ A further complication in the present context arises from the fact that, over the sample considered, the Bank of England's Monetary Policy Committee (MPC) meets twelve times a year, while official forecasts are updated once a quarter. We use surprises from the first short sterling futures contracts. These pay the 3-month sterling LIBOR that is realized on the day of expiry. The conditioning set over which the orthogonal monetary surprises are calculated is in this case composed by (a) forecasts and forecast revisions for output and

\footnotetext{
${ }^{22}$ See Appendix A.
} 
inflation for the previous and the current quarter and up to three quarters ahead, and for current unemployment, extracted from the quarterly Inflation Report, and (b) the lagged Bank Rate and the lagged level of the LiBor-OIS spread. The use of Inflation Report forecasts as a proxy for the Bank of England's information set is also used in Cloyne and Hürtgen (2016) to construct a narrative account of UK monetary policy decisions not taken in response to current and forecast macroeconomic conditions in the spirit of Romer and Romer (2004). The inclusion of the LIBOR-OIS spread is intended to partially offset the fact that the contracts used to extract the surprises are not a direct function of the interest rate set by the MPC. Being linked to the sterling LIBOR, the raw surprises in short sterling futures are rather a measure of the expected change in the 3month interbank rate and, to the extent that the relation between the two rates is neither zero, nor constant, it needs to be controlled for when extracting revisions in expectations about the policy rate. ${ }^{23}$ The raw UK monetary surprise used is the one computed around rate announcements only. The orthogonal surprise $\mathrm{SS}^{\star}{ }^{\star}$ is plotted in Figure III against its raw counterpart ss1 for the period 2001-2015. While IR forecasts are released at quarterly frequency and with no significant lag, and thus their timely availability is not a concern, we end the benchmark sample for the identification in 2009 to avoid introducing potential distortions caused by Bank Rate reaching its effective lower bound (ELB). The orthogonal surprise calculated over the benchmark sample only is plotted in Appendix B (Figure B.III). The start date for the construction of the orthogonal surprise is instead constrained by the availability of the LIBOR-OIS spread. It is worth noticing that the largest peak in the raw surprise disappears in the orthogonal series, in support to the claim that not all price movements contemporaneous to policy announcements are necessarily a reaction to monetary policy shocks only. In fact, the peak coincides with the sharp forecast revisions to growth and unemployment at the onset of the 2009 recession and the sudden increase in the LiBOR-OIS spread that occurred in late 2008, and that was signalling increased fears of insolvency and concerns related to credit availability which had arguably little to do with the monetary policy decision.

\footnotetext{
${ }^{23}$ See Figure A.II. Ideally, one would want the correction for the LIBOR-OIS spread to happen at the time of computing the surprises at intraday frequency; however, due to unavailability of intraday swap quotes for the selected period, the daily spread is used instead.
} 


\subsection{Identification of Monetary Policy Shocks}

In the remainder of this section we illustrate the implications of the orthogonalization proposed above for the identification of monetary policy shocks. To this end, we intentionally rely on small monetary VARs for both the US and the UK to let the differences between the different instruments stand out. For each of the two countries we rely on the same VAR and only alter the way in which the monetary policy shocks are identified. Specifically, we keep fixed the VAR specification, the sample, and the set of endogenous variables and use alternatively the original and orthogonal monetary surprises as external instruments for the identification. As a result, the IRFs will display the same type of dynamics, which are governed by the estimated autoregressive coefficients. Conversely, any differences between the estimated dynamic responses can be directly attributed to differences in the external instruments used for the identification.

US We test the implications for monetary shock identification using the FF4 and FF $4{ }^{\star}$ series as external instruments in a Proxy SVAR where the monetary policy variable is the end-of-month 1-year government bond rate. The use of the fourth federal funds future in conjunction with the one year rate is borrowed from Gertler and Karadi (2015), and is intended to capture both conventional and unconventional monetary policy likely to affect interest rates at medium maturities during the zero lower bound period. Other endogenous variables are the log of industrial production, the unemployment rate, the log of CPI and a commodity price index. All variables are taken from the St. Louis FRED Database, with the exception of the commodity price index, distributed by the Commodity Research Bureau. The composition of the set is the same as in Coibion (2012) and Ramey (2016). For the sake of completeness and comparability with results in these papers, impulse response functions (IRFs) to a monetary policy shock identified using a recursive Cholesky scheme with the effective federal funds rate replacing the 1-year rate and ordered last are also reported. The VAR is estimated in levels with 12 lags over the period 1969:1 - 2014:12. The identification sample is 1990:1 - 2009:12 and corresponds to the full length of the orthogonal $\mathrm{FF}^{\star}$. Responses are normalized such that the policy rate increases on impact by $1 \%$. Results are in Figure IV. Dashed yellow lines are for 
the recursive identification scheme with the federal funds rate ordered last - CHOL. Dark blue (dash-dotted) lines are obtained when the shock is identified using the FF4-based surprise (PSVAR) of Gertler and Karadi (2015) - PSVAR. Red lines are responses obtained when the orthogonal $\mathrm{FF}^{\star}{ }^{\star}$ surprise series is used instead - PSVAR ${ }^{\star}$. Shaded areas are $68 \%$ and $90 \%$ bootstrapped confidence bands obtained with 10,000 replications; the wild bootstrap of Gonçalves and Kilian (2004) is used.

\section{[ INSERT Figure IV ABOUT HERE ]}

Differences between the three identifications are stark. IRFs from both CHOL and PSVAR lie outside the confidence bands of PSVAR ${ }^{\star}$ in almost all cases, and particularly so for the nearer horizons. The issues highlighted for the raw FF4 measures (see also Appendix A), coupled with a small, presumably informationally deficient VAR, deliver distorted and counterintuitive responses for both industrial output and unemployment. Gertler and Karadi (2015) use the weighted FF4 measure to identify effects of the monetary policy shock in a similarly small VAR where, however, they also include the excess bond premium (EBP) of Gilchrist and Zakrajšek (2012). Other than being a good predictor of real activity, the EBP is constructed using micro-level data on corporate spreads with average maturity of about 7 years. The long maturity of spreads involved in the calculation of the EBP is likely to be at least partially capturing also forecasts about future realizations that 'clean' the VAR residuals and thus still deliver responses of the expected sign. ${ }^{2425}$ On the other hand, PSVAR ${ }^{\star}$ responses are less reliant on the composition of the information set in the VAR, and carry a more conventional sign. Once the anticipation effects are accounted for, the IRFs depict a recessionary scenario as a consequence of the

\footnotetext{
${ }^{24}$ As noted, successful identification of the shocks in a Proxy SVAR depends both on the quality of the proxy and on the correct specification of the VAR. The importance of the inclusion of the Excess Bond Premium for the identification of the monetary policy shock in otherwise informationally deficient VARs is also discussed in Caldara and Herbst (2015).

${ }^{25}$ The positive responses of output and unemployment are in this case amplified by the use of the average monthly markets surprise (i.e. the one in Gertler and Karadi, 2015). When the monthly sum of daily surprises is used instead, that is, no weighting is performed on the daily monetary surprises as is the case for example in Stock and Watson (2012), the expansionary effects induced by the nowcast updates and the contractionary effects induced by the monetary policy shock balance out, resulting in muted responses at all horizons for both output and unemployment in the same VAR used here. IRFs for this case are not reported but available upon request. Further details on the weighting scheme are in Appendix A.
} 
monetary contraction. Although necessarily less precise, PSVAR ${ }^{\star}$ responses are robust to sample splits and reported in Appendix B (Figure B.I).

UK We build a similar setup to study the effects of the orthogonalization in Eq. (16) in the UK. The monetary policy shock is identified using alternatively the raw Ss1 and the orthogonal $\mathrm{Ss} 1^{\star}$ as external instruments, and the monetary policy variable is again the end-of-month 1-year government bond rate. Other endogenous variables are the log of industrial production, the LFS (Labour Force Survey) unemployment rate and the log of the retail price index (RPI). ${ }^{26}$ Data for Bank Rate and the 1-year government bond rate are from the Bank of England; prices, output and unemployment data are from the Office of National Statistics. The VAR is estimated in levels with 12 lags over the period 1979:1 to $2014: 12$; responses are again normalized such that the policy rate increases by $1 \%$ on impact. The sample used for the identification of the contemporaneous transmission coefficients excludes the ELB period and goes from 2001:1 to 2009:12. Responses obtained using the orthogonal $\mathrm{Ss}^{\star}{ }^{\star}$ extended to include the ELB period are essentially unaltered, but estimated with a substantial degree of uncertainty, and reported in Figure B.IV. ${ }^{27}$

\section{[ INSERT Figure V ABOUt HERE ]}

Responses to a monetary policy shock in the UK are in Figure V. As before, dashed yellow lines are for the recursive identification scheme where Bank Rate is ordered last (CHOL). Dark blue dash-dotted lines are obtained when the shock is identified using the raw SS1-based surprise (PSVAR). Red lines are responses obtained when the orthogonal $\mathrm{SS}^{\star}{ }^{\star}$ surprise series is used - PSVAR ${ }^{\star}$. Responses in Figure V confirm the extent to which the estimates of the contemporaneous transmission coefficients can be distorted when raw surprises are used to proxy for the monetary policy shock. Again, CHOL and PSVAR responses lie outside the PSVAR ${ }^{\star}$ confidence bands throughout most of the horizons, and particularly so on impact. Moreover, as was the case for the US, the spurious information

\footnotetext{
${ }^{26}$ Before 1997 the Bank of England's used the RPI to calibrate its inflation target.

${ }^{27}$ A further backward extension to June 1997 (not reported) is obtained by assuming that the LIBOROIS spread is constant and equal to its pre-crisis average over the period 1997:6 - 2000:12. IRFs in this case are qualitatively the same, but again estimated with significantly greater uncertainty.
} 
included in the raw Ss1 produces responses for output, unemployment and prices that are hard, if not impossible, to reconcile with economic theory. It is important to notice here that all MPC meeting are scheduled, and that therefore the presence of anticipatory effects affects monetary surprises irrespective of the nature of the policy meeting they refer to. The responses in Figure B.II, obtained when the RPI is replaced with the consumer price index and the VAR is estimated from 1990:1 to 2014:12, show that again the identification is robust to sample splits, and the composition of the VAR information set.

\section{Concluding Remarks}

Identification of the effects of monetary policy requires isolating exogenous shifts in the policy variable that are not the expression of the systematic response of the central bank to actual or foreseen changes in the economic environment. The use of monetary surprises as an identification device implicitly assumes that market participants can correctly account for the systematic component of policy when they are surprised by an interest rate decision. And that therefore monetary policy shocks are the only reason why prices adjust following the announcement.

We show that this is not necessarily the case, and that in fact monetary surprises are also a function of the disagreement between central banks' and private sector forecasts. Whenever there is scope for the two sets of forecasts to differ, the monetary surprises cannot be thought of as being exogenous, or assumed to be isolating the correct signal.

Monetary surprises are predictable by central banks' forecasts and by public data released before the announcements. This lends support to our theory, and has important consequences for the estimation of the dynamic responses to the shock. Contrary to what would happen with a valid external instrument, the predictability of monetary surprises makes the choice of the modelling framework, and of the type and number of variables included in the system, crucial for the correct identification of the shocks. In the extreme case in which no controls for future expectations are included, and the VAR is specified only on a handful of variables, raw surprises can recover responses to monetary policy shocks that have signs opposite to what macroeconomic theory predicts. 
We develop a new set of proxies for monetary policy shocks that are free of anticipatory effects and unpredictable by past information. We achieve this by projecting the raw surprises on a conditioning set that includes central banks' forecasts and forecast revisions of the main variables that are likely to enter the policy rule. We use the residuals to identify monetary policy shocks. These orthogonal surprises retrieve responses of the main output and price variables that have the desired sign in the same informationally deficient VARs. 


\section{References}

Altavilla, Carlo, Domenico Giannone, and Michele Modugno (2014) "Low Frequency Effects of Macroeconomic News on Government Bond Yields," Working Papers ECARES ECARES 2014-34, ULB - Universite Libre de Bruxelles.

Andrade, Philippe and Filippo Ferroni (2016) "Were the ECB announcements Odyssean or Delphic?" mimeo, Banque de France.

Bagliano, Fabio C. and Carlo A. Favero (1999) "Information from financial markets and VAR measures of monetary policy," European Economic Review, Vol. 43, No. 4-6, pp. 825-837, April.

Barakchian, S. Mahdi and Christopher Crowe (2013) "Monetary policy matters: Evidence from new shocks data," Journal of Monetary Economics, Vol. 60, No. 8, pp. 950-966.

Caldara, Dario and Edward Herbst (2015) "Monetary Policy, Credit Spreads, and Business Cycle Fluctuations," mimeo, Board of Governors of the Federal Reserve System (U.S.).

Campbell, Jeffrey R., Charles L. Evans, Jonas D.M. Fisher, and Alejandro Justiniano (2012) "Macroeconomic Effects of Federal Reserve Forward Guidance," Brookings Papers on Economic Activity, Vol. 44, No. 1 (Spring), pp. 1-80.

Campbell, Jeffrey R., Jonas D. M. Fisher, Alejandro Justiniano, and Leonardo Melosi (2016) "Forward Guidance and Macroeconomic Outcomes Since the Financial Crisis," in NBER Macroeconomics Annual 2016, Volume 31: National Bureau of Economic Research, Inc.

Cesa-Bianchi, Ambrogio, Gregory Thwaites, and Alejandro Vicondoa (2016) "Monetary Policy Transmission in an Open Economy: New Data and Evidence from the United Kingdom," Discussion Paper 2016-12, CFM.

Cieslak, Anna (2016) "Short-Rate Expectations and Unexpected Returns in Treasury Bonds," Technical report, Available at SSRN: https://ssrn.com/abstract=2239725 or http://dx.doi.org/10.2139/ssrn.2239725.

Cloyne, James and Patrick Hürtgen (2016) "The Macroeconomic Effects of Monetary Policy: A New Measure for the United Kingdom," American Economic Journal: Macroeconomics, Vol. 8, No. 4, pp. 75-102, October.

Cochrane, John H. and Monika Piazzesi (2002) "The Fed and Interest Rates: A HighFrequency Identification," NBER Working Papers 8839, National Bureau of Economic Research, Inc.

Coibion, Olivier (2012) "Are the Effects of Monetary Policy Shocks Big or Small?," American Economic Journal: Macroeconomics, Vol. 4, No. 2, pp. 1-32, April.

Cook, Timothy and Thomas Hahn (1989) "The effect of changes in the federal funds rate target on market interest rates in the 1970s," Journal of Monetary Economics, Vol. 24, No. 3, pp. $331-351$. 
Fama, Eugene F (1990) “Stock Returns, Expected Returns, and Real Activity," Journal of Finance, Vol. 45, No. 4, pp. 1089-1108, September.

Fama, Eugene F. (2013) "Two Pillars of Asset Pricing," December. Nobel Prize Lecture.

Fama, Eugene F. and Kenneth R. French (1989) "Business conditions and expected returns on stocks and bonds," Journal of Financial Economics, Vol. 25, No. 1, pp. 23 49.

Forni, Mario and Luca Gambetti (2014) "Sufficient information in structural VARs," Journal of Monetary Economics, Vol. 66, No. C, pp. 124-136.

Forni, Mario, Marc Hallin, Marco Lippi, and Lucrezia Reichlin (2000) "The Generalized Dynamic-Factor Model: Identification and Estimation," Review of Economics and Statistics, Vol. 82, No. 4, pp. 540-554.

Galí, Jordi (2008) Monetary Policy, Inflation, and the Business Cycle: An Introduction to the New Keynesian Framework: Princeton University Press.

Gertler, Mark and Peter Karadi (2015) "Monetary Policy Surprises, Credit Costs, and Economic Activity," American Economic Journal: Macroeconomics, Vol. 7, No. 1, pp. $44-76$.

Gilchrist, Simon and Egon Zakrajšek (2012) "Credit Spreads and Business Cycle Fluctuations," American Economic Review, Vol. 102, No. 4, pp. 1692-1720.

Glick, Reuven and Sylvain Leduc (2015) "Unconventional monetary policy and the dollar: conventional signs, unconventional magnitudes," Working Paper Series 2015-18, Federal Reserve Bank of San Francisco.

Gonçalves, Silvia and Lutz Kilian (2004) "Bootstrapping autoregressions with conditional heteroskedasticity of unknown form," Journal of Econometrics, Vol. 123, No. 1, pp. 89120, November.

Gürkaynak, Refet S (2005) "Using federal funds futures contracts for monetary policy analysis," Finance and Economics Discussion Series 2005-29, Board of Governors of the Federal Reserve System (U.S.).

Gürkaynak, Refet S, Brian Sack, and Eric T. Swanson (2005) "Do Actions Speak Louder Than Words? The Response of Asset Prices to Monetary Policy Actions and Statements," International Journal of Central Banking, Vol. 1, No. 1, May.

(2006) "Market-based Measures of Monetary Policy Expectations," Working Paper Series 2006-04, Federal Reserve Bank of San Francisco.

Hanson, Samuel G. and Jeremy C. Stein (2015) "Monetary policy and long-term real rates," Journal of Financial Economics, Vol. 115, No. 3, pp. 429-448.

Joyce, Michael, Jonathan Relleen, and Steffen Sorensen (2008) "Measuring Monetary Policy Expectations from Financial Market Instruments," Working Paper Series 0978, European Central Bank. 
Kuttner, Kenneth N. (2001) "Monetary policy surprises and interest rates: Evidence from the Fed funds futures market," Journal of Monetary Economics, Vol. 47, No. 3, pp. 523-544, June.

Lucca, David O. and Emanuel Moench (2015) "The Pre-FOMC Announcement Drift," The Journal of Finance, Vol. 70, No. 1, pp. 329-371.

McCracken, Michael W. and Serena Ng (2015) "FRED-MD: A Monthly Database for Macroeconomic Research," Working Papers 2015-12, Federal Reserve Bank of St. Louis.

Melosi, Leonardo (2017) "Signaling Effects of Monetary Policy," Review of Economic Studies, forthcoming.

Mertens, Karel and Morten O. Ravn (2013) "The Dynamic Effects of Personal and Corporate Income Tax Changes in the United States," American Economic Review, Vol. 103, No. 4, pp. 1212-47.

Miranda-Agrippino, Silvia and Giovanni Ricco (2016) "The Transmission of Monetary Policy Shocks." University of Warwick.

Montiel-Olea, José Luis, James H. Stock, and Mark W. Watson (2016) "Uniform Inference in SVARS Identified with External Instruments." New York University.

Nakamura, Emi and Jón Steinsson (2017) "High Frequency Identification of Monetary Non-Neutrality: The Information Effect," The Quarterly Journal of Economics, forthcoming.

Piazzesi, Monika (2002) "The Fed and Interest Rates - A High-Frequency Identification," American Economic Review, Vol. 92, No. 2, pp. 90-95, May.

Ramey, Valerie A. (2016) "Macroeconomic Shocks and Their Propagation," Working Paper 21978, National Bureau of Economic Research.

Rogers, John H., Chiara Scotti, and Jonathan H. Wright (2014) "Evaluating Asset-Market Effects of Unconventional Monetary Policy: A Cross-Country Comparison," International Finance Discussion Papers 1101, Board of Governors of the Federal Reserve System (U.S.).

Romer, Christina D. and David H. Romer (2000) "Federal Reserve Information and the Behavior of Interest Rates," American Economic Review, Vol. 90, No. 3, pp. 429-457. (2004) "A New Measure of Monetary Shocks: Derivation and Implications," American Economic Review, Vol. 94, No. 4, pp. 1055-1084.

Rudebusch, Glenn D. (1998) "Do Measures of Monetary Policy in a Var Make Sense?" International Economic Review, Vol. 39, No. 4, pp. 907-931.

Sack, Brian (2004) "Extracting the Expected Path of Monetary Policy From Futures Rates," Journal of Futures Markets, Vol. 24, No. 8, pp. 733-754. 
Scotti, Chiara (2013) "Surprise and uncertainty indexes: real-time aggregation of realactivity macro surprises," International Finance Discussion Papers 1093, Board of Governors of the Federal Reserve System (U.S.).

Sims, Christopher A. (1992) "Interpreting the macroeconomic time series facts: The effects of monetary policy," European Economic Review, Vol. 36, No. 5, pp. 975-1000, June.

Soderlind, Paul and Lars Svensson (1997) "New techniques to extract market expectations from financial instruments," Journal of Monetary Economics, Vol. 40, No. 2, pp. 383429, October.

Stock, James H. and Mark W. Watson (2002) "Macroeconomic Forecasting Using Diffusion Indexes," Journal of Business $\&$ Economic Statistics, Vol. 20, No. 2, pp. 147-162.

(2012) "Disentangling the Channels of the 2007-09 Recession," Brookings Papers on Economic Activity, Vol. 44, No. 1, pp. 81-156.

(2017) "Identification and Estimation of Dynamic Causal Effects in Macroeconomics." Sargan Lecture, Royal Economic Society.

Svensson, Lars E.O. (1994) "Estimating and Interpreting Forward Interest Rates: Sweden 1992 - 1994," NBER Working Papers 4871, National Bureau of Economic Research, Inc.

Swanson, Eric T. (2015) "Measuring the Effects of Unconventional Monetary Policy on Asset Prices," NBER Working Papers 21816, National Bureau of Economic Research, Inc.

Vissing-Jorgensen, Annette, Adair Morse, and Anna Cieslak (2015) "Stock returns over the FOMC cycle," 2015 Meeting Papers 1197, Society for Economic Dynamics.

Woodford, Michael (2003) Interest and Prices: Foundations of a Theory of Monetary Policy: Princeton University Press. 


\section{FIGURE I: MONETARY POLICY SHOCKS AND FORECAST UPDATES IN MONETARY SURPRISES}
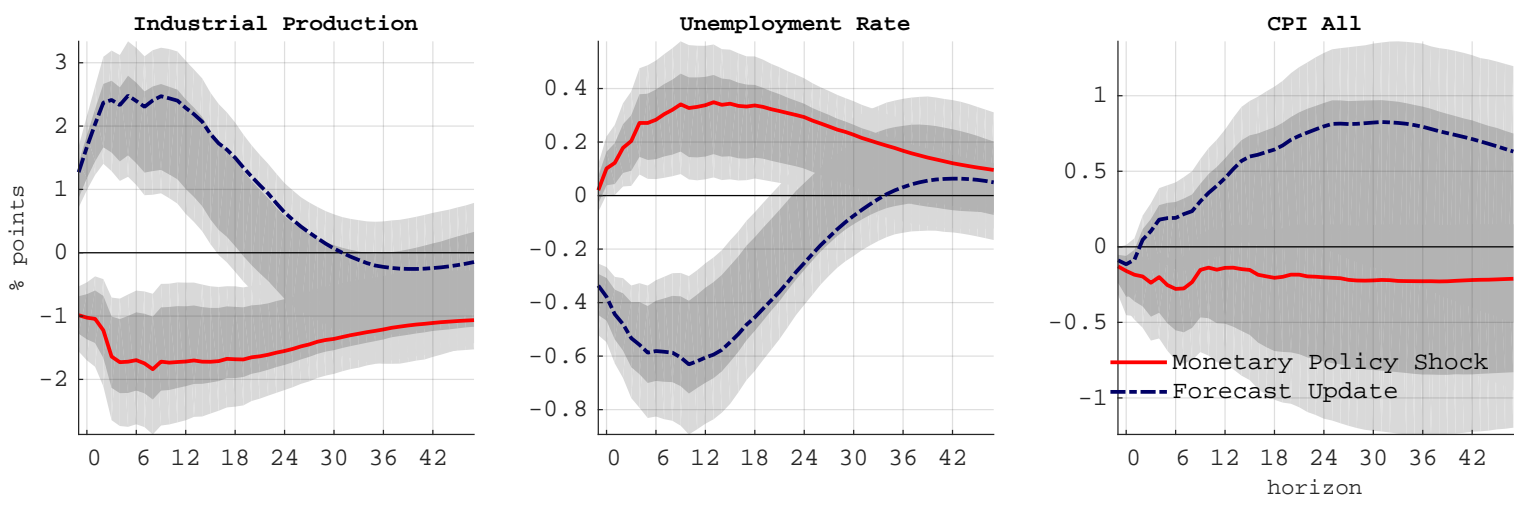

Notes: Responses of variables to the components in market-based monetary surprises. IRFs normalized to induce 100bp increase in the policy rate. VAR(12) estimated in levels over 1969:1 - 2014:12. The monetary policy variable is the 1-year rate. Shaded areas are 68 and $90 \%$ confidence bands obtained using 10,000 bootstrap replications. 
FIgURE II: ORTHOGONAL MONETARY SURPRISES IN FOURTH FEDERAL FUNDS FUTURES

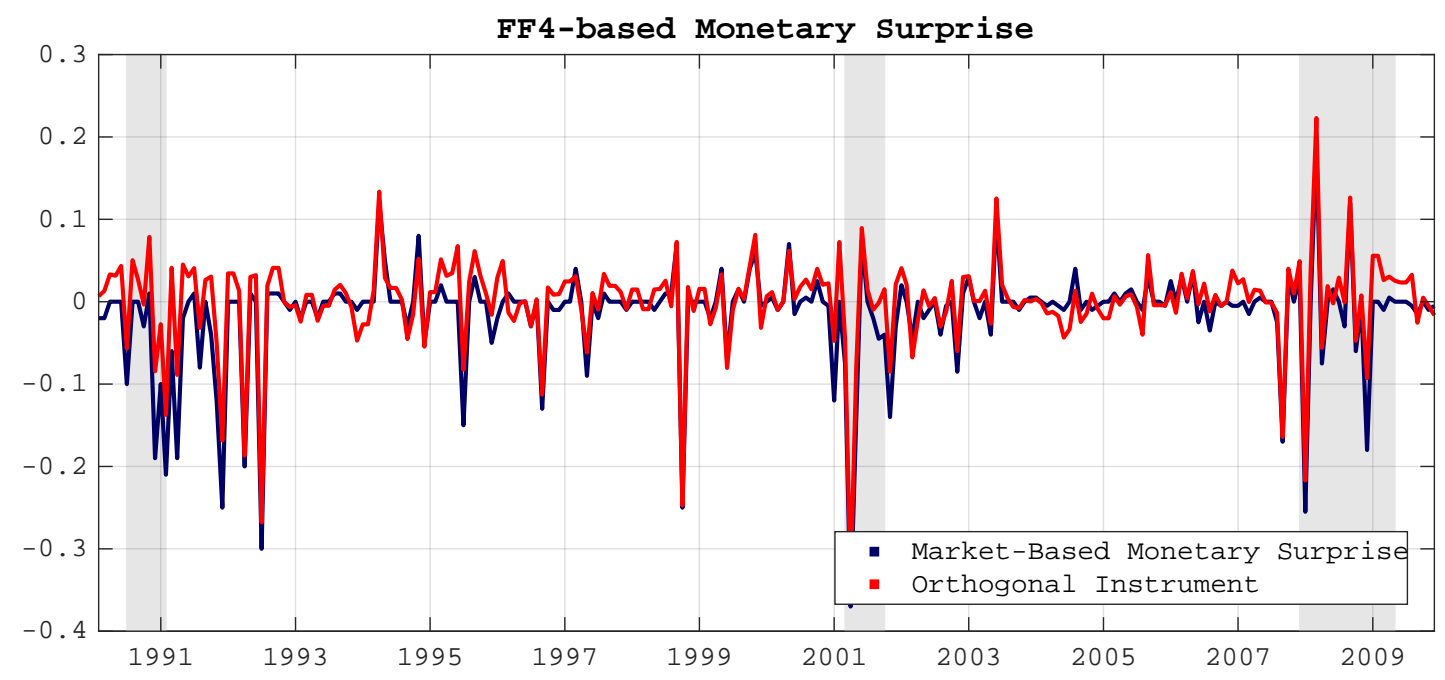

Notes: Raw (FF4 - blue line) and orthogonal (FF4 ${ }^{\star}$ - red line) monetary surprises for the US at monthly frequency. Both sets of surprises are extracted from the fourth federal funds futures contract. Shaded areas denote NBER recessions. 
FIGURE III: ORTHOGONAL MONETARY SURPRISES IN FIRST SHORT STERLING FUTURES: EXTENDED IDENTIFICATION SAMPLE

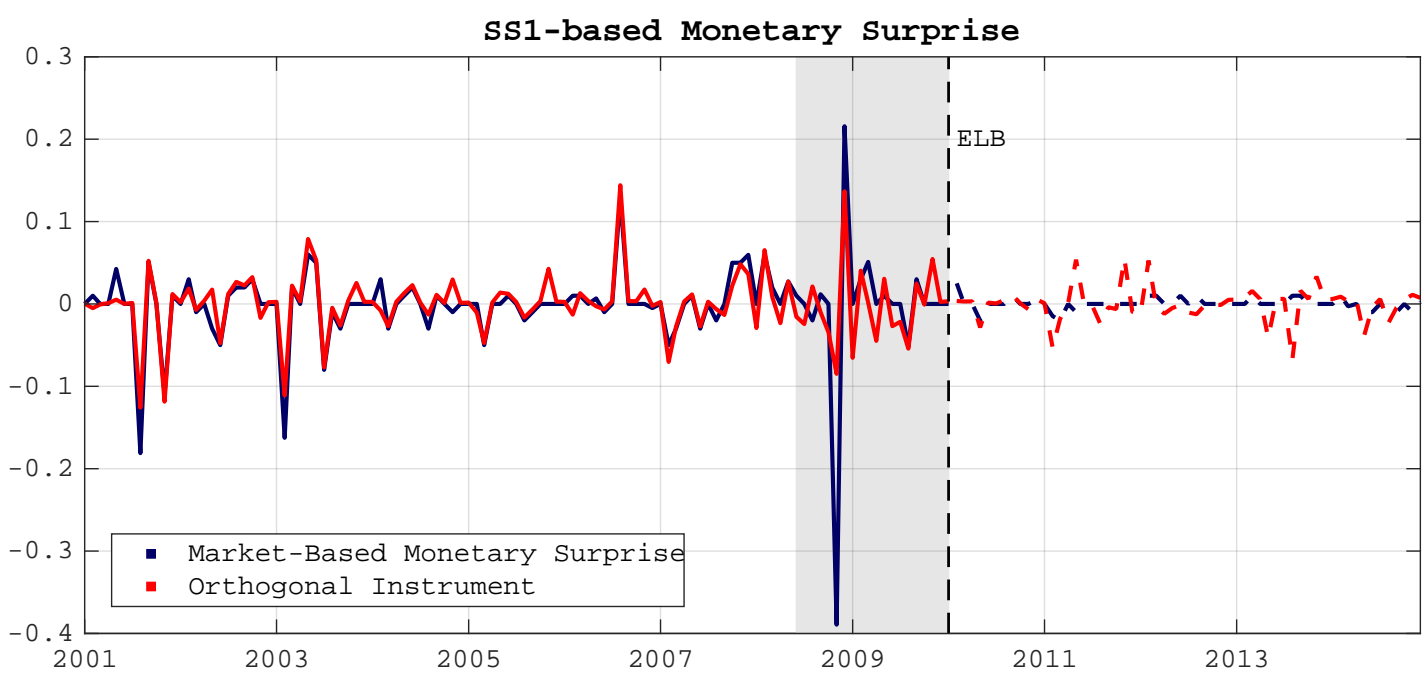

Notes: Raw (ss1 - blue line) and orthogonal (ss1 ${ }^{\star}$ - red line) monetary surprises for the UK at monthly frequency. Both sets of surprises are extracted from the first short sterling futures contract. Shaded areas denote Economic Cycle Research Institute (ECRI) recessions. The vertical dotted line denotes start of the Effective Lower Bound (ELB) zone. 
FigURE IV: RESPONSES TO A CONTRACTIONARY MONETARY POLICY SHOCK IN THE US: RAW AND ORTHOGONAL MONETARY SURPRISES
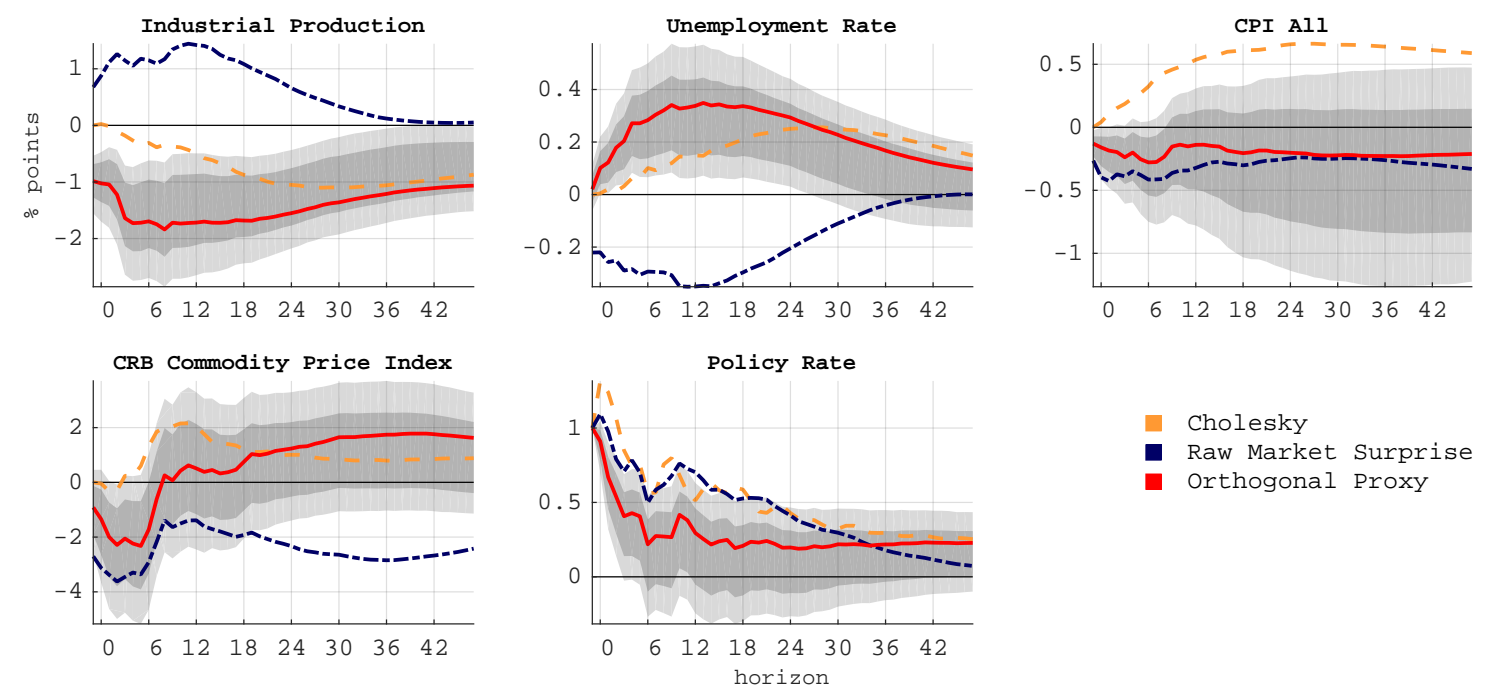

Notes: VAR(12) over the sample 1969:1 - 2014:12. Identification with orthogonal monetary surprises $\left(\mathrm{FF} 4^{\star}\right.$, red solid lines), raw monetary surprises (FF4, blue dash-dotted lines), and recursive ordering (policy rate ordered last, yellow dashed lines). Shaded areas are $68 \%$ and $90 \%$ bootstrapped confidence bands. IRFs normalized to a $1 \%$ impact increase in the policy rate. 
Figure V: RESPONSES TO A CONTRACTIONARY MONETARY POLICY SHOCK IN THE UK: RAW AND ORTHOGONAL MONETARY SURPRISES IN SMALL VAR
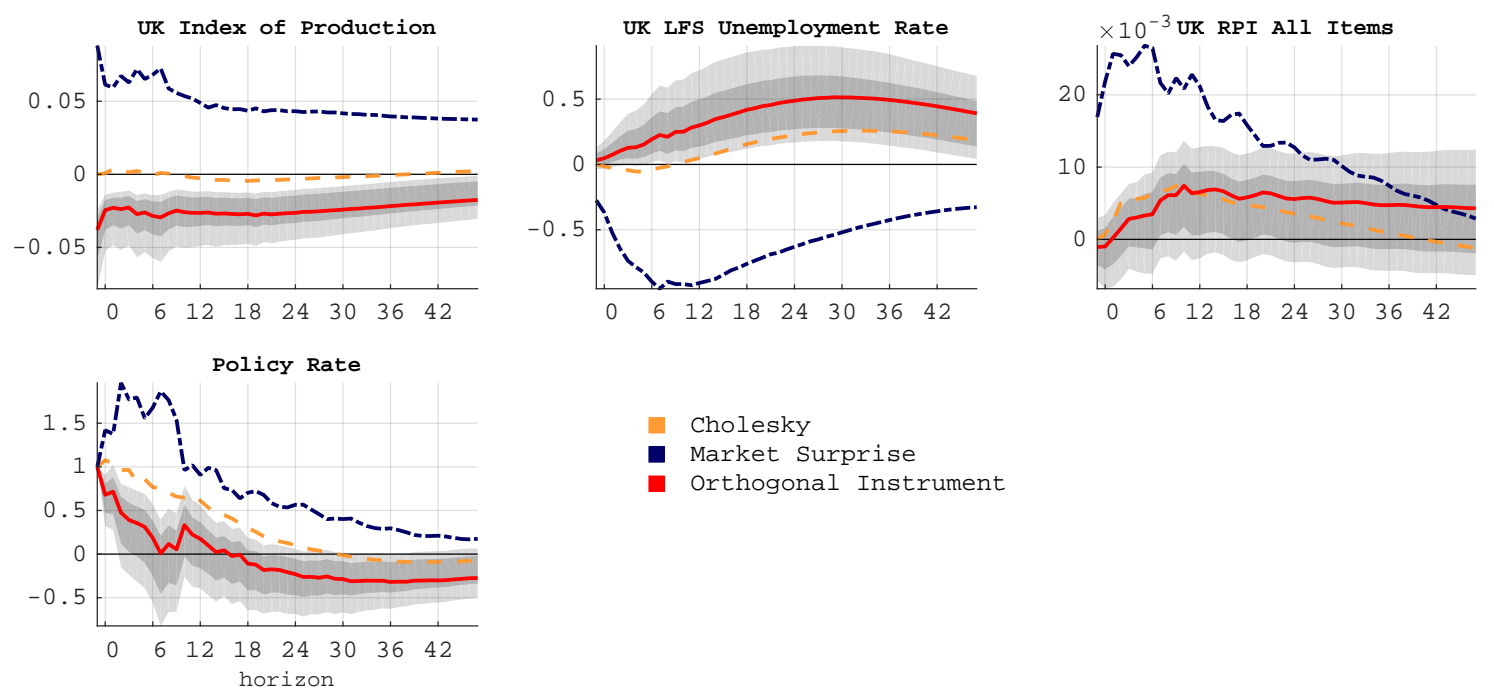

- Cholesky

- Market Surprise

- Orthogonal Instrument

Notes: VAR(12) over the sample 1979:1 - 2014:12. Identification with orthogonal monetary surprises ( $\mathrm{ss} 1^{\star}$, red solid lines), raw monetary surprises (ss1, blue dash-dotted lines), and recursive ordering (policy rate ordered last, yellow dashed lines). Shaded areas are $68 \%$ and $90 \%$ bootstrapped confidence bands. IRFs normalized to a $1 \%$ impact increase in the policy rate. 
Table I: Predictability of Monetary Surprises: Central Bank Forecasts

\begin{tabular}{|c|c|c|c|c|c|c|c|c|c|c|}
\hline \multirow[b]{2}{*}{$\Delta y_{t \mid t}^{\mathrm{GB}}$} & \multicolumn{2}{|c|}{$M P 1_{t}$} & \multicolumn{2}{|c|}{$F F 4_{t}$} & \multicolumn{2}{|c|}{$E D 2_{t}$} & \multicolumn{2}{|c|}{$E D 3_{t}$} & \multicolumn{2}{|c|}{$E D 4_{t}$} \\
\hline & 0.013 & {$[1.48]$} & 0.012 & {$[2.02]^{* *}$} & 0.012 & {$[1.75]^{*}$} & 0.013 & {$[1.86]^{*}$} & 0.013 & {$[1.96]^{*}$} \\
\hline$\Delta y_{t+1 \mid t}^{\mathrm{GB}}$ & 0.040 & {$[2.90]^{* * *}$} & 0.028 & {$[2.31]^{* *}$} & 0.034 & {$[2.75]^{* * *}$} & 0.030 & {$[2.33]^{* *}$} & 0.021 & {$[1.81]^{*}$} \\
\hline$\Delta y_{t+2 \mid t}^{\mathrm{GB}}$ & -0.035 & {$[-1.81]^{*}$} & -0.023 & {$[-1.84]^{*}$} & -0.017 & {$[-1.35]$} & -0.004 & {$[-0.40]$} & 0.007 & [0.68] \\
\hline$\Delta \pi_{t \mid t}^{\mathrm{GB}}$ & -0.004 & {$[-0.30]$} & 0.004 & {$[0.37]$} & 0.009 & {$[0.58]$} & 0.01 & {$[0.64]$} & 0.010 & {$[0.67]$} \\
\hline$\Delta \pi_{t+1 \mid t}^{\mathrm{GB}}$ & -0.010 & {$[-0.47]$} & -0.003 & {$[-0.17]$} & -0.017 & {$[-0.96]$} & -0.017 & {$[-0.94]$} & -0.011 & {$[-0.62]$} \\
\hline$\Delta \pi_{t+2 \mid t}^{\mathrm{GB}}$ & 0.044 & [1.39] & 0.036 & {$[1.67]^{*}$} & 0.045 & {$[2.09]^{* *}$} & 0.047 & {$[2.10]^{* *}$} & 0.042 & {$[1.85]^{*}$} \\
\hline$\Delta u_{t \mid t}^{\mathrm{GB}}$ & 0.109 & [1.49] & 0.094 & {$[2.23]^{* *}$} & 0.155 & {$[2.37]^{* *}$} & 0.141 & {$[2.13]^{* *}$} & 0.147 & {$[2.10]^{* *}$} \\
\hline$\Delta u_{t+1 \mid t}^{\mathrm{GB}}$ & -0.311 & {$[-2.02]^{* *}$} & -0.305 & {$[-2.83]^{* * *}$} & -0.316 & {$[-2.80]^{* * *}$} & -0.270 & {$[-2.52]^{* *}$} & -0.250 & {$[-2.38]^{* *}$} \\
\hline$\Delta u_{t+2 \mid t}^{\mathrm{GB}}$ & 0.156 & {$[1.30]$} & 0.156 & {$[1.76]^{*}$} & 0.119 & {$[1.54]$} & 0.084 & {$[1.13]$} & 0.068 & {$[0.96]$} \\
\hline
\end{tabular}

Note: Regressions include a constant and 4 lags of the dependent variable. 1990:2009. From left to right, the monthly surprise in the first and fourth federal funds futures $\left(M P 1_{t}\right.$ and $\left.F F 4_{t}\right)$, and in the second $\left(E D 2_{t}\right)$, third $\left(E D 3_{t}\right)$, and fourth $\left(E D 4_{t}\right)$ Eurodollar futures. September 2001 not included. $\Delta y^{\mathrm{GB}}$, $\Delta \pi^{\mathrm{GB}}$ and $\Delta u^{\mathrm{GB}}$ denote Greenbook forecast revisions between consecutive meetings for output, inflation and unemployment. t-statistics are reported in square brackets, ${ }^{*} p<0.1,{ }^{* *} p<0.05,{ }^{* * *} p<0.01$, robust standard errors. 
Table II: Predictability of Monetary Surprises: Past Information

\begin{tabular}{|c|c|c|c|c|c|c|c|c|c|c|}
\hline \multirow[b]{2}{*}{$f_{1, t-1}$} & \multicolumn{2}{|c|}{$M P 1_{t}$} & \multicolumn{2}{|c|}{$F F 4_{t}$} & \multicolumn{2}{|c|}{$E D 2_{t}$} & \multicolumn{2}{|c|}{$E D 3_{t}$} & \multicolumn{2}{|c|}{$E D 4_{t}$} \\
\hline & -0.014 & {$[-1.51]$} & -0.011 & {$[-1.67]^{*}$} & -0.021 & {$[-3.05]^{* * *}$} & -0.023 & {$[-3.25]^{* * *}$} & -0.021 & {$[-3.21]^{* * *}$} \\
\hline$f_{2, t-1}$ & 0.003 & {$[0.63]$} & 0.002 & {$[0.74]$} & 0.004 & {$[1.07]$} & 0.004 & {$[1.18]$} & 0.004 & {$[1.07]$} \\
\hline$f_{3, t-1}$ & -0.01 & {$[-1.50]$} & 0.002 & {$[0.37]$} & 0.003 & {$[0.63]$} & 0.003 & {$[0.58]$} & 0.004 & {$[0.72]$} \\
\hline$f_{4, t-1}$ & 0.015 & {$[1.43]$} & 0.015 & {$[2.05]^{* *}$} & 0.015 & {$[2.07]^{* *}$} & 0.015 & {$[2.02]^{* *}$} & 0.013 & {$[1.91]^{*}$} \\
\hline$f_{5, t-1}$ & 0.003 & {$[0.34]$} & 0.001 & {$[0.21]$} & -0.001 & {$[-0.14]$} & 0.001 & {$[0.15]$} & 0.004 & {$[0.57]$} \\
\hline$f_{6, t-1}$ & -0.013 & {$[-2.02]^{* *}$} & -0.012 & {$[-2.19]^{* *}$} & -0.011 & {$[-1.89]^{*}$} & -0.012 & {$[-1.90]^{*}$} & -0.013 & {$[-2.18]^{* *}$} \\
\hline$f_{7, t-1}$ & -0.014 & {$[-1.32]$} & -0.007 & {$[-0.98]$} & -0.009 & {$[-1.21]$} & -0.01 & {$[-1.33]$} & -0.009 & {$[-1.35]$} \\
\hline$f_{8, t-1}$ & -0.004 & {$[-0.70]$} & -0.002 & {$[-0.49]$} & -0.001 & {$[-0.16]$} & -0.001 & {$[-0.27]$} & 0.000 & {$[0.07]$} \\
\hline$f_{9, t-1}$ & 0.002 & {$[0.26]$} & -0.003 & {$[-0.68]$} & -0.008 & {$[-1.63]$} & -0.006 & {$[-1.32]$} & -0.006 & {$[-1.26]$} \\
\hline$f_{10, t-1}$ & 0.000 & {$[0.01]$} & 0.005 & {$[0.84]$} & 0.003 & {$[0.71]$} & 0.003 & {$[0.64]$} & 0.004 & {$[0.74]$} \\
\hline$f_{1, t-1}^{*}$ & 0.022 & {$[2.36]^{* *}$} & 0.015 & {$[2.30]^{* *}$} & 0.020 & {$[2.78]^{* * *}$} & 0.022 & {$[3.17]^{* * *}$} & 0.021 & {$[3.12]^{* * *}$} \\
\hline$f_{2, t-1}^{*}$ & -0.011 & {$[-1.73]^{*}$} & -0.004 & {$[-0.75]$} & -0.005 & {$[-0.88]$} & -0.005 & {$[-0.84]$} & -0.005 & {$[-0.92]$} \\
\hline$f_{3, t-1}^{*}$ & 0.006 & [1.51] & 0.006 & {$[1.47]$} & 0.011 & {$[2.34]^{* *}$} & 0.013 & {$[2.62]^{* * *}$} & 0.014 & {$[3.14]^{* * *}$} \\
\hline$f_{4, t-1}^{*}$ & 0.014 & {$[1.73]^{*}$} & 0.006 & {$[0.95]$} & 0.004 & {$[0.70]$} & 0.004 & {$[0.65]$} & 0.003 & {$[0.49]$} \\
\hline$f_{5, t-1}^{*}$ & -0.006 & {$[-0.79]$} & -0.002 & {$[-0.37]$} & -0.003 & {$[-0.57]$} & -0.003 & {$[-0.57]$} & -0.003 & {$[-0.62]$} \\
\hline
\end{tabular}

Note: TOP PANEL: factors extracted from the set of monthly variables in McCracken and $\mathrm{Ng}(2015)$. BOTTOM PANEL: factors extracted from the set of monthly variables in McCracken and $\mathrm{Ng}$ (2015) that are not subject to revision. Regressions include a constant and 4 lags of the dependent variable. 1990:2009. From left to right, the monthly surprise in the first and fourth federal funds futures $\left(M P 1_{t}\right.$ and $\left.F F 4_{t}\right)$, and in the second $\left(E D 2_{t}\right)$, third $\left(E D 3_{t}\right)$, and fourth $\left(E D 4_{t}\right)$ Eurodollar futures. September 2001 not included. t-statistics are reported in square brackets, ${ }^{*} p<0.1,{ }^{* *} p<0.05,{ }^{* * *} p<0.01$, robust standard errors. 
Table III: Predictability of UK Monetary Surprises: Central Bank FORECASTS

\begin{tabular}{lcccccc}
\hline & \multicolumn{2}{c}{$S S 1_{t}$} & \multicolumn{2}{c}{$S S 1 M_{t}$} & \multicolumn{3}{c}{$S S 1 M I R_{t}$} \\
\cline { 2 - 7 }$\Delta y_{t \mid t}^{\mathrm{IR}}$ & -0.023 & {$[-0.31]$} & -0.042 & {$[-0.51]$} & -0.051 & {$[-0.64]$} \\
$\Delta y_{t+1 \mid t}^{\mathrm{IR}}$ & 0.042 & {$[0.54]$} & 0.042 & {$[0.52]$} & 0.085 & {$[1.10]$} \\
$\Delta y_{t+2 \mid t}^{\mathrm{IR}}$ & 0.046 & {$[0.76]$} & 0.06 & {$[0.94]$} & 0.058 & {$[0.80]$} \\
$\Delta \pi_{t \mid t}^{\mathrm{IR}}$ & -0.05 & {$[-0.73]$} & -0.053 & {$[-0.87]$} & -0.126 & {$[-1.76]^{*}$} \\
$\Delta \pi_{t+1 \mid t}^{\mathrm{IR}}$ & 0.013 & {$[0.11]$} & -0.013 & {$[-0.11]$} & 0.107 & {$[0.76]$} \\
$\Delta \pi_{t+2 \mid t}^{\mathrm{IR}}$ & 0.052 & {$[0.46]$} & 0.072 & {$[0.62]$} & 0.027 & {$[0.19]$} \\
$\Delta u_{t \mid t}^{\mathrm{IR}}$ & -0.245 & {$[-1.28]$} & -0.281 & {$[-1.34]$} & -0.243 & {$[-1.00]$} \\
$\Delta u_{t+1 \mid t}^{\mathrm{IR}}$ & 0.576 & {$[1.72]^{*}$} & 0.705 & {$[1.91]^{*}$} & 0.764 & {$[1.76]^{*}$} \\
$\Delta u_{t+2 \mid t}^{\mathrm{IR}}$ & -0.431 & {$[-2.03]^{* *}$} & -0.51 & {$[-2.21]^{* *}$} & -0.601 & {$[-2.17]^{* *}$} \\
\hline
\end{tabular}

Note: Regressions include a constant and 4 lags of the dependent variable. 2001:2009. From left to right, the monthly surprise in the first short sterling futures at rate announcement dates $\left(S S 1_{t}\right)$, rate announcement and minutes release $\left(S S 1 M_{t}\right)$, rate, minutes and release of the IR $\left(S S 1 M I R_{t}\right) . \Delta y^{\mathrm{IR}}, \Delta \pi^{\mathrm{IR}}$ and $\Delta u^{\mathrm{IR}}$ denote Inflation Report forecast revisions for output, inflation and unemployment. t-statistics are reported in square brackets, ${ }^{*} p<0.1,{ }^{* *} p<0.05,{ }^{* * *} p<0.01$, robust standard errors. 
Table IV: Predictability of UK Monetary Surprises: Past Information

\begin{tabular}{lrlrlrl}
\hline & \multicolumn{2}{c}{$S S 1_{t}$} & \multicolumn{2}{c}{$S S 1 M_{t}$} & \multicolumn{2}{c}{$S S 1 M I R_{t}$} \\
\cline { 2 - 9 }$f_{1, t-1}$ & -0.007 & {$[-0.67]$} & -0.008 & {$[-0.72]$} & -0.019 & {$[-1.42]$} \\
$f_{2, t-1}$ & 0.006 & {$[1.09]$} & 0.005 & {$[0.89]$} & 0.002 & {$[0.34]$} \\
$f_{3, t-1}$ & 0.005 & {$[0.86]$} & 0.005 & {$[0.83]$} & 0.007 & {$[1.06]$} \\
$f_{4, t-1}$ & -0.011 & {$[-1.27]$} & -0.011 & {$[-1.29]$} & -0.016 & {$[-1.70]^{*}$} \\
$f_{5, t-1}$ & -0.015 & {$[-1.79]^{*}$} & -0.015 & {$[-1.76]^{*}$} & -0.02 & {$[-2.04]^{* *}$} \\
$f_{6, t-1}$ & -0.012 & {$[-1.54]$} & -0.011 & {$[-1.44]$} & -0.013 & {$[-1.43]$} \\
$f_{7, t-1}$ & 0.011 & {$[1.56]$} & 0.013 & {$[1.71]^{*}$} & 0.017 & {$[1.89]^{*}$} \\
$f_{8, t-1}$ & 0.003 & {$[0.73]$} & 0.005 & {$[1.00]$} & 0.007 & {$[1.28]$} \\
$f_{9, t-1}$ & 0.012 & {$[1.18]$} & 0.013 & {$[1.25]$} & 0.019 & {$[1.53]$} \\
$f_{10, t-1}$ & 0.001 & {$[0.21]$} & 0.003 & {$[0.44]$} & 0.005 & {$[0.82]$} \\
$f_{1, t-1}^{*}$ & 0.000 & {$[-0.05]$} & 0.000 & {$[-0.03]$} & 0.007 & {$[0.62]$} \\
$f_{2, t-1}^{*}$ & 0.013 & {$[1.29]$} & 0.012 & {$[1.21]$} & 0.017 & {$[1.45]$} \\
$f_{3, t-1}^{*}$ & 0.001 & {$[0.14]$} & 0.000 & {$[0.00]$} & -0.003 & {$[-0.49]$} \\
$f_{4, t-1}^{*}$ & -0.007 & {$[-1.07]$} & -0.005 & {$[-0.76]$} & -0.003 & {$[-0.35]$} \\
$f_{5, t-1}^{*}$ & -0.011 & {$[-1.19]$} & -0.012 & {$[-1.28]$} & -0.015 & {$[-1.40]$} \\
\hline
\end{tabular}

Note: TOP PANEL: macro-financial factors extracted from last vintage data. BOTTOM PANEL: macrofinancial factors extracted from unrevised data. Regressions include a constant and 4 lags of the dependent variable. 2001:2009. From left to right, the monthly surprise in the first short sterling futures at rate announcement dates $\left(S S 1_{t}\right)$, rate announcement and minutes release $\left(S S 1 M_{t}\right)$, rate, minutes and release of the IR $\left(S S 1 M I R_{t}\right)$. t-statistics are reported in square brackets, ${ }^{*} p<0.1,{ }^{* *} p<0.05, * * *$ $p<0.01$, robust standard errors. 
Table V: Orthogonal Surprises and Past Information

\begin{tabular}{|c|c|c|c|c|c|c|c|c|c|c|}
\hline \multirow[b]{2}{*}{$f_{1, t-1}$} & \multicolumn{2}{|c|}{$M P 1_{t}^{\star}$} & \multicolumn{2}{|c|}{$F F 4_{t}^{\star}$} & \multicolumn{2}{|c|}{$E D 2_{t}^{\star}$} & \multicolumn{2}{|c|}{$E D 3_{t}^{\star}$} & \multicolumn{2}{|c|}{$E D 4_{t}^{\star}$} \\
\hline & 0.005 & {$[0.65]$} & 0.003 & {$[0.44]$} & 0.004 & {$[0.65]$} & 0.002 & {$[0.36]$} & 0.001 & {$[0.22]$} \\
\hline$f_{2, t-1}$ & 0.003 & {$[0.56]$} & 0.002 & {$[0.66]$} & 0.004 & {$[1.29]$} & 0.005 & {$[1.25]$} & 0.004 & [1.18] \\
\hline$f_{3, t-1}$ & 0.004 & {$[0.74]$} & 0.008 & {$[1.64]$} & 0.009 & {$[1.88]^{*}$} & 0.009 & {$[1.70]^{*}$} & 0.007 & {$[1.45]$} \\
\hline$f_{4, t-1}$ & 0.010 & {$[1.09]$} & 0.011 & {$[1.66]^{*}$} & 0.008 & {$[1.21]$} & 0.008 & {$[1.24]$} & 0.007 & [1.05] \\
\hline$f_{5, t-1}$ & 0.001 & {$[0.12]$} & -0.002 & {$[-0.31]$} & 0.000 & {$[-0.04]$} & 0.001 & {$[0.19]$} & 0.003 & {$[0.38]$} \\
\hline$f_{6, t-1}$ & -0.008 & {$[-1.39]$} & -0.007 & {$[-1.35]$} & -0.005 & {$[-0.86]$} & -0.005 & {$[-0.89]$} & -0.006 & {$[-1.12]$} \\
\hline$f_{7, t-1}$ & -0.009 & {$[-0.94]$} & -0.007 & {$[-1.09]$} & -0.007 & {$[-1.06]$} & -0.009 & {$[-1.37]$} & -0.01 & {$[-1.45]$} \\
\hline$f_{8, t-1}$ & -0.005 & {$[-0.91]$} & -0.001 & {$[-0.37]$} & 0.002 & {$[0.45]$} & 0.002 & {$[0.49]$} & 0.004 & {$[0.91]$} \\
\hline$f_{9, t-1}$ & 0.000 & {$[-0.02]$} & -0.004 & {$[-0.93]$} & -0.007 & {$[-1.51]$} & -0.005 & {$[-1.12]$} & -0.004 & {$[-0.89]$} \\
\hline$f_{10, t-1}$ & -0.006 & {$[-1.02]$} & -0.001 & {$[-0.12]$} & 0.000 & {$[-0.07]$} & -0.001 & {$[-0.16]$} & 0.001 & {$[0.16]$} \\
\hline$f_{1, t-1}^{*}$ & -0.001 & {$[-0.14]$} & -0.001 & {$[-0.12]$} & -0.004 & {$[-0.68]$} & -0.002 & {$[-0.36]$} & -0.001 & {$[-0.11]$} \\
\hline$f_{2, t-1}^{*}$ & 0.000 & {$[-0.06]$} & 0.001 & {$[0.15]$} & -0.001 & {$[-0.13]$} & -0.001 & {$[-0.18]$} & -0.002 & {$[-0.31]$} \\
\hline$f_{3, t-1}^{*}$ & 0.001 & {$[0.39]$} & 0.002 & {$[0.76]$} & 0.005 & {$[1.40]$} & 0.006 & {$[1.58]$} & 0.007 & {$[1.92]^{*}$} \\
\hline$f_{4, t-1}^{*}$ & 0.009 & {$[1.23]$} & 0.004 & {$[0.83]$} & 0.002 & {$[0.30]$} & 0.002 & {$[0.44]$} & 0.003 & {$[0.50]$} \\
\hline$f_{5, t-1}^{\star}$ & 0.001 & {$[0.24]$} & 0.005 & {$[1.11]$} & 0.005 & {$[1.01]$} & 0.006 & {$[1.28]$} & 0.006 & {$[1.18]$} \\
\hline$F-s t a t$ & 0.74 & $(0.592)$ & 0.92 & $(0.470)$ & 0.92 & $(0.471)$ & 1.29 & $(0.267)$ & 1.47 & $(0.201)$ \\
\hline
\end{tabular}

Note: TOP PANEL: factors extracted from the set of monthly variables in McCracken and $\mathrm{Ng}(2015)$. BOTTOM PANEL: factors extracted from the set of monthly variables in McCracken and $\mathrm{Ng}$ (2015) that are not subject to revision. Regressions include a constant and 4 lags of the dependent variable. 1990:2009. From left to right, the component of monetary surprises orthogonal to central bank's forecasts in the first and fourth federal funds futures $\left(M P 1_{t}^{\star}\right.$ and $\left.F F 4_{t}^{\star}\right)$, and in the second $\left(E D 2_{t}^{\star}\right)$, third $\left(E D 3_{t}^{\star}\right)$, and fourth $\left(E D 4_{t}^{\star}\right)$ Eurodollar futures. September 2001 not included. t-statistics are reported in square brackets, ${ }^{*} p<0.1,{ }^{* *} p<0.05,{ }^{* * *} p<0.01$, robust standard errors. In the last row, ne null hypothesis is that all the coefficients of the unrevised factors are jointly zero, p-values in parentheses. 


\section{A Monetary Surprises from Futures on Interest Rates}

\section{A.1 US Raw Monetary Surprises}

Sack (2004) discusses the technical procedure for the extraction of policy expectations from both Federal Funds (FF) and Eurodollar (ED) futures. These are shown to be accurate predictors of the policy rate in Gürkaynak, Sack and Swanson (2006). Let $f f^{(h)}$ and $e d^{(h)}$ denote respectively the price of the FF and ED expiring on day $h$ of a given month with $N$ days then:

$$
\begin{aligned}
& f f^{(h)}=100-\frac{1}{N} \sum_{j=1}^{N} i_{j}, \\
& e d^{(h)}=100-\$ \operatorname{lib}_{h}^{(h+90)},
\end{aligned}
$$

where $i_{t}$ is the effective fed funds rate and $\$ \operatorname{lib}_{h}^{(h+90)}$ is the 3-month US dollar LIBOR fixing on day $h$. When expressed in rates, the equations above transform as follows:

$$
\begin{aligned}
p_{t, F F}^{(h)} & =\mathbb{E}_{t}\left(\frac{1}{N} \sum_{j=1}^{N} i_{j}\right)+\zeta_{F F, t}^{(h)}, \\
p_{t, E D}^{(h)} & =\mathbb{E}_{t}\left[\$ \operatorname{lib}{ }_{h}^{(h+90)}\right]+\zeta_{E D, t}^{(h)} \\
& =\mathbb{E}_{t}\left[\overline{\mathbf{i}}_{h}^{h+90}\right]+\mathbb{E}_{t}\left[\$ \operatorname{lib}_{h}^{(h+90)}-\overline{\mathbf{i}}_{h}^{h+90}\right]+\zeta_{E D, t}^{(h)} .
\end{aligned}
$$

$\overline{\mathbf{i}}_{h}^{h+90}$ denotes the average rates over the 90 days (3 months) starting from day $h$, i.e. $\overline{\mathbf{i}}_{h}^{h+90} \equiv \frac{1}{90} \sum_{j=1}^{90} i_{h+j}$. While the link between FF and $i_{t}$ is direct, when dealing with EDs an additional step in which expectations about future LIBOR fixings are translated into expectations about the policy rate is required. The terms $\zeta_{, t}^{(h)}$ denote (possibly timevarying) term/risk premia in both equations. In Eq. (A.4), the ED rate is expressed as a function of three terms: $(a)$ the expectation of the short-term rate over the three-month period starting from the expiration of the contract - $h$; $(b)$ a term reflecting 'basis risk', that is, the compensation that investors require for lending to an institution over a 3month period rather than on an overnight basis; and $(c)$ a residual risk premium which encompasses everything that is not explicitly associated to either $(a)$ or $(b)$.

Kuttner (2001) constructs monetary surprises in the US using daily data on federal funds futures expiring in the current month. Gürkaynak (2005) and Gürkaynak et al. (2005) use futures covering maturities which go out about 3.5 quarters and intraday quotes. Federal funds futures settle based on the average effective federal funds rate 
(EFFR) calculated over the relevant expiry month, therefore, if $f f_{t-\Delta t}^{(0)}$ denotes the current month futures just before $(-\Delta t)$ the FOMC meeting, and $i_{t}$ is the EFFR:

$$
f f_{t-\Delta t}^{(0)}=\frac{n}{N} \mathbb{E}_{t-\Delta t}\left[i_{\tau \leq t}\right]+\frac{N-n}{N} \mathbb{E}_{t-\Delta t}\left[i_{\tau \geq t}\right]+\zeta_{F F, t-\Delta t}^{(0)}
$$

In the equation above, $N$ is the number of days in the month and $n$ is the day of the FOMC meeting, $t$ the time of the announcement, and $\zeta_{F F, t-\Delta t}^{(0)}$ a risk or term premium that may be present in the contract. The scaling is such that it avoids overweighting when the FOMC meets at the end of the month by using the next month's contract if certain timing criteria are met (see Gürkaynak, 2005). The monetary policy surprise $m p s_{t}^{(0)}$ - can be computed as:

$$
\begin{aligned}
m p s_{t}^{(0)} & =\frac{N}{N-n}\left[f f_{t}^{(0)}-f f_{t-\Delta t}^{(0)}\right] \\
& =\left(\mathbb{E}_{t}\left[i_{\tau \geq t}\right]-\mathbb{E}_{t-\Delta t}\left[i_{\tau \geq t}\right]\right)+\left(\zeta_{F F, t}^{(0)}-\zeta_{F F, t-\Delta t}^{(0)}\right) .
\end{aligned}
$$

Gürkaynak et al. (2005) assume that the latter term in the equation above is zero, de facto implying that it takes longer than the $\Delta t$ time frame for the announcement to modify the premium. The surprises that relate to announcements further ahead in the future are derived in an equivalent way using futures that refer to the month in which the relevant FOMC announcement is scheduled to happen.

The raw monetary surprise extracted from the fourth fed funds futures (FF4) and aggregated at monthly frequency is plotted in Figure A.I. The top panel of the chart reports the monthly average surprise in Gertler and Karadi (2015) (blue line) and the raw series that assigns each daily surprise in Gürkaynak, Sack and Swanson (2005) to the month in which the corresponding meeting was scheduled to happen (red line). ${ }^{28}$ The bottom row of the chart reports (from left to right) the scatter plot of the two monthly measures and the partial autocorrelation function of the weighted and unweighted monthly surprises respectively. The weighted series exhibits some degree of autocorrelation, also noted in Ramey (2016). The weighting procedure of Gertler and Karadi (2015) can be summarised in two steps: (1) for each day of the month, the surprise is equal to the sum of surprises in FOMC days within the past month; (2) for each month, the surprise is equal to the average of the daily series in the previous step. The procedure induces a significant time-dependence in the monthly series. To see this, note that the autocorrelation is only marginally significant when monthly surprises are just the sum of daily movements (unweighted series). A more serious concern, however, is in the alignment

\footnotetext{
${ }^{28}$ The procedure follows Romer and Romer (2004); if there is more than one FOMC meeting in the same month, the monthly surprise is equal to the sum of the surprises registered in that month.
} 

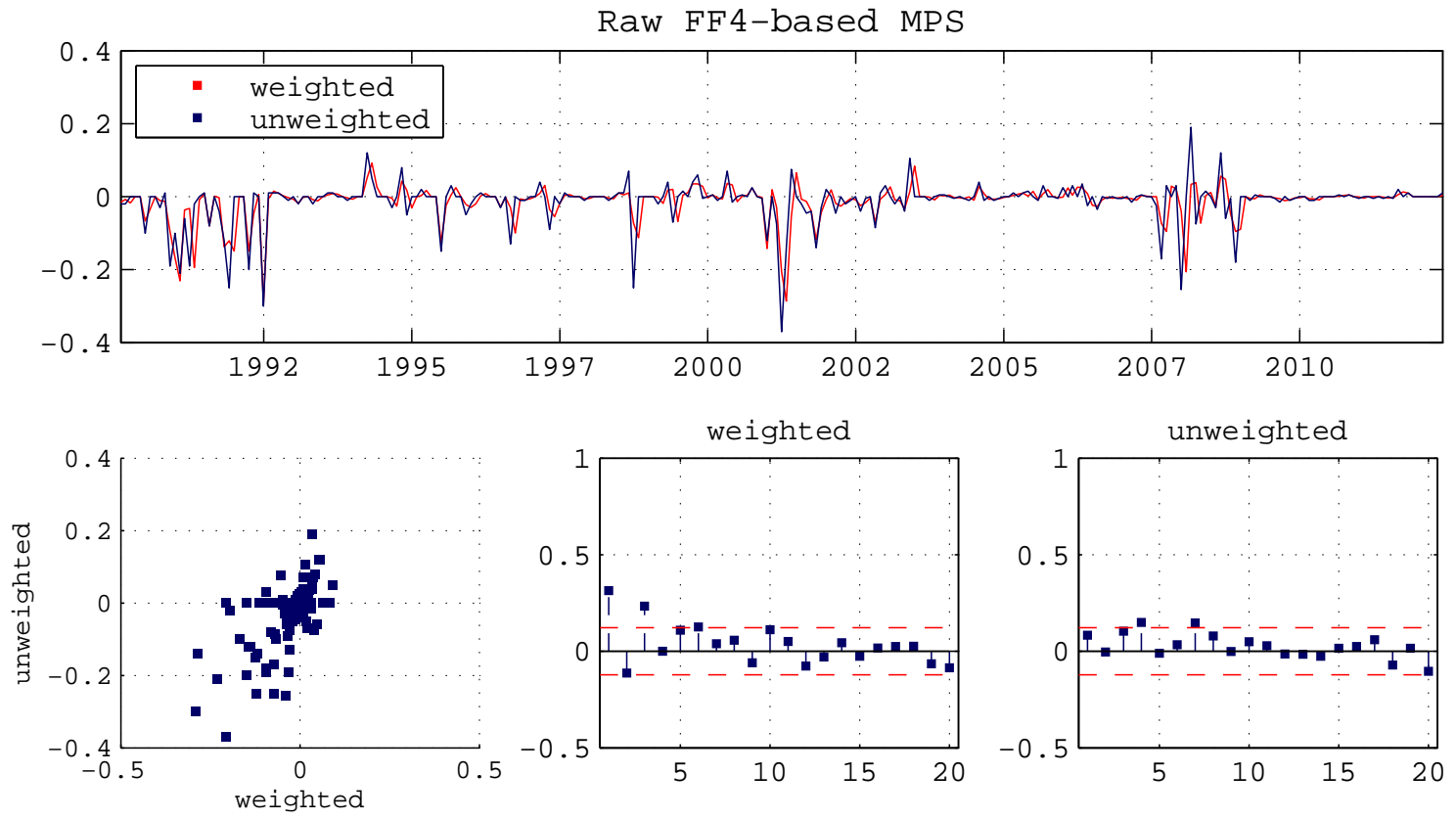

Notes: Raw FF4-based monetary surprises at monthly frequency. The weighted series is from Gertler and Karadi (2015). The unweighted surprise is constructed as the sum of daily surprises in Gürkaynak et al. (2005). In the bottom panel, from left to right, the different information content in the two series and their partial autocorrelation functions.

of the two series, visible in the top panel of the chart. The weighting of daily surprises shifts the monthly surprise series forward; this implies that also the alignment with the information set (and thus the residuals) of the VAR is distorted. As a result, we use the unweighted monthly surprises as the basis for our analysis.

\section{A.2 UK Raw Monetary Surprises}

The case for the UK differs form the US in some non-trivial ways. The Bank of England implements the Monetary Policy Committee's (MPC) decisions by adjusting the level of Bank Rate, to which no financial market instrument is directly linked. The closest alternative is Overnight Indexed Swap (OIS) contracts. In these contracts, the parties agree to exchange fixed interest rate payments against payments based on the Sterling Overnight Index Average (SONIA). Because the level of credit risk in overnight transactions is typically very low, SONIA rates track Bank Rate closely. Furthermore, and for the same reason, the implied path of SONIA rates at short horizons should also be relatively free of material risk premia. The contracts, however, are only available for a limited time span and, until the years immediately preceding the global financial crisis, 
seldom traded at maturities beyond 6 months. The next best alternative is to use short sterling (SS) futures contracts, whose forecasting performance is only slightly inferior to OIS rates. ${ }^{29}$ These contracts settle based on the 3-month interbank (GBP) LIBOR rate rather than on overnight rates, but are exchange-traded and available for a much longer history.

Because Eurodollar (ED) futures also settle on the (US dollar) LIBOR rather than on the effective fed funds rate, they are the natural starting point to work out policy expectations in the UK. Building on the decomposition in Sack (2004) - Eq. (A.4) -, let $s s^{(h)}$ denote the price of a short sterling futures expiring on day $h$. We have that

$$
s s^{(h)}=100-£ \operatorname{lib}_{h}^{(h+90)},
$$

where $£ \operatorname{lib}_{h}^{(h+90)}$ is the 3-month sterling LiBOR fixing on day $h$. Following the same logic in Eq.(A.4), the rate at time $t$ can then be expressed as

$$
\begin{aligned}
p_{t, s s}^{(h)} & =\mathbb{E}_{t}\left[£ \operatorname{lib}_{h}^{(h+90)}\right]+\zeta_{S S, t}^{(h)}, \\
& =\mathbb{E}_{t}\left[\overline{\mathbf{i}}_{h}^{h+90}\right]+\mathbb{E}_{t}\left[£ \operatorname{lib}_{h}^{(h+90)}-\overline{\mathbf{i}}_{h}^{h+90}\right]+\zeta_{S S, t}^{(h)},
\end{aligned}
$$

where it is assumed that the overnight rate $i_{t}$ is equivalent to the policy rate up to a negligible additive error. $\overline{\mathbf{i}}_{h}^{h+90}$ denotes the average overnight rate over the 90 days (3 months) starting from day $h$, i.e. $\overline{\mathbf{i}}_{h}^{h+90} \equiv \frac{1}{90} \sum_{j=1}^{90} i_{h+j}$.

The rates involved in Eq. (A.8) and a detail on the time variation of the LIBOR-OIS spread are in Figure A.II for the sample 01/01/2000 - 31/05/2015. The overnight rate is the one that most closely tracks the policy rate over the whole sample considered. The 3-month LIBOR on the other hand typically lies above the policy/overnight rates reflecting the risk involved in lending at further away maturities. While it is now widely regarded as one of the key measures of credit risk premia, the LIBOR-OIS spread - i.e. the second term in Eq. (A.8), drew relatively little attention in the years preceding the onset of the financial crisis: its level remained very low (around 11bps) and substantially flat for years, reflecting the belief that the level of credit risk involved in the financial system was not only very small, but also constant. Starting from 2008, however, doubts

\footnotetext{
${ }^{29}$ The quality of market-based policy path forecasts, including those derived from SS contracts, is discussed in Joyce, Relleen and Sorensen (2008). The exercise is similar in spirit to Gürkaynak, Sack and Swanson (2006), but in this case also yield curves are added to the horserace. The two zero-coupon yield curves used in the analysis are the ones estimated and published by the Bank of England; the Government Liability Curve (GLC), derived from UK government bonds ('gilts') and general collateral repo rates, and the Bank Liability Curve (BLC), based instead on LIBOR interest rates, short sterling futures, Forward Rates Agreements and LiBOR-based interest rates swaps. Since yield curves are estimated and published at daily frequency, we discard them from the subsequent analysis.
} 


\section{Figure A.II: COMPONENTS OF SHORT STERLING FUTURES}
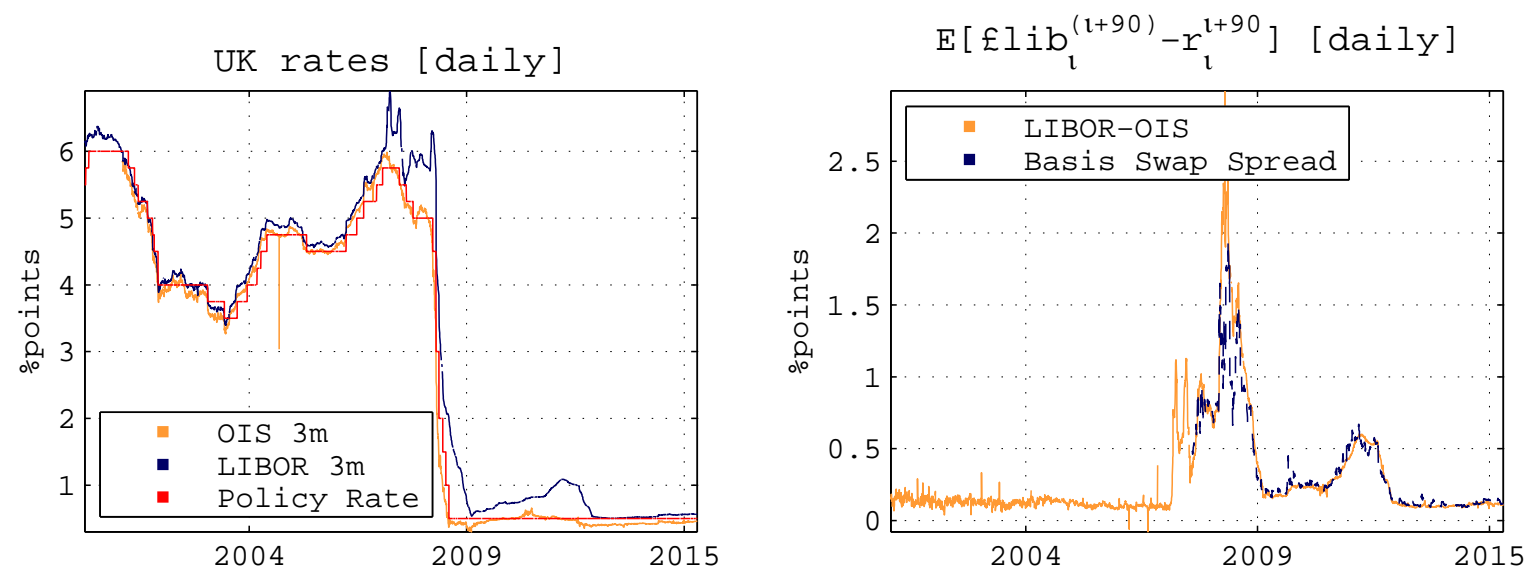

Notes: [LEFT] Relevant interest rates for short sterling futures rates decomposition. [RIGHT] LIBOR-OIS spreads obtained as the difference between the 3-month sterling LIBOR and the 3-month OIS curve, and from basis swaps (front contract, basis swap spread). All rates are at daily frequency over the sample 01/01/2000 - 31/05/2015. See equation (A.8) for details. Source: Bloomberg, author calculations.

about financial institutions' solvency and concerns related to market liquidity induced a rise in LiBors which made the spread jump to unprecedented levels. As the LiBor-OIS spread moved away from its long-run average, basis swaps involving expected risk at different maturities started being traded and thus, from that date, expectations about future spreads can be read from the swap quotes. In the absence of such contracts, that is prior to 2008, the actual difference between the 3-month sterling LIBOR and the 3-month OIS curve can be used to compute the expected spread. This is equivalent to setting $h=0$ in $\mathbb{E}_{t}\left[£ \operatorname{lib}_{h}^{(h+90)}-\overline{\mathbf{i}}_{h}^{h+90}\right]$.

Let $p_{t, B S}^{(h)}$ denote the basis swap quotes matching the expectation components in Eq. (A.8) at any time $t$, and let the relevant policy announcement happen within the time interval $[t-\Delta t, t]$, such that $\Delta t$ denotes the width of the time window around which the response is measured. In the absence of any conflicting event the raw monetary policy surprise is given by:

$$
\begin{aligned}
m p s_{t}^{(h)} & =\left(p_{t, S S}^{(h)}-p_{t-\Delta t, S S}^{(h)}\right)-\left(p_{t, B S}^{(h)}-p_{t-\Delta t, B S}^{(h)}\right), \\
& =\left(\mathbb{E}_{t}\left[\overline{\mathbf{i}}_{h}^{h+90}\right]-\mathbb{E}_{t-\Delta t}\left[\overline{\mathbf{i}}_{h}^{h+90}\right]\right)+\left(\zeta_{t}^{(h)}-\zeta_{t-\Delta t}^{(h)}\right) .
\end{aligned}
$$

Figure A.III plots the monthly surprises in the first short sterling futures from June 1997 to 2015. The starting date is chosen to coincide with the first decision meeting after the MPC independence. SS delivery dates are such that the first three contracts 
expire towards the end of three consecutive months, the first of which is the current one. ${ }^{30}$ To construct the raw monetary surprise, at any date in the sample we use the next expiring SS futures, or front contract (SS1). Because liquidity in these markets tends to become very thin when the expiration date approaches, if the MPC date falls in the vicinity of the expiry date, the next contract is used instead. The top panel of the chart compares monthly surprises measured around announcement only (blue line) and all policy-relevant events in the same month, that is, the release of the minutes and of the Inflation Report (red dotted line). Surprises are computed in narrow 30-minute windows tightly surrounding the policy event. The historical set of policy rate decisions dates and times, and the decision that resulted from the committee meetings are reconstructed using Bloomberg. A different strategy is adopted in case of the release of the Inflation Report: due to the press conference associated with the release lasting a full hour, more flexibility is allowed in this case by employing a 90-minute window. Raw intraday data are from Thomson Reuters Tick History Database. For the construction of the monthly surprise we again follow Romer and Romer (2004) and assign each surprise to the month of the corresponding announcement.

In a non-negligible number of instances within the sample considered, some of the policy-relevant events around which the surprises are computed are contemporaneous to major macroeconomic data release. While the Bank Rate decision is typically released to the public at 12:00 noon, when no other data releases are scheduled, the release of the minutes and of the Inflation Report (IR) are contemporaneous to a number of relevant data releases that are also likely to substantially influence markets. ${ }^{31}$ This is particularly true for the release of the minutes of the MPC meetings, the date and time of which often coincide with the release of labour market data and statistics on money and lending activities and, in some instances, GDP figures. To account for these interferences, in all cases we control for (standardized) data news falling within the time window around which the surprise is measured. Data news are computed as the difference between the released value and the median nowcast of the Bloomberg Survey of Economists as in Scotti (2013) and Altavilla, Giannone and Modugno (2014).

The top panel and the bottom left subplot of Figure A.III reveal that while there are some differences between the two series, expanding the set of policy events to include the minutes and the IR does not seem to modify substantially the overall information content of the monthly surprise series. We take this as evidence of the fact that on

\footnotetext{
${ }^{30}$ https://www. theice.com/products/37650330/Three-Month-Sterling-Short-Sterling-Future

${ }^{31}$ In the summer of 2015 the Bank of England adopted a different release schedule whereby the rate announcement and the minutes of the meeting are released simultaneously to the public at 12 noon. When the IR is also due for release, it is added to the block (e.g. "super Thursday" of August 6th, 2015).
} 
FigURE A.III:

INFORMATIONAL CONTENT OF UK-BASED MONETARY SURPRISES CALCULATED ON DIFFERENT SETS OF POLICY EVENTS
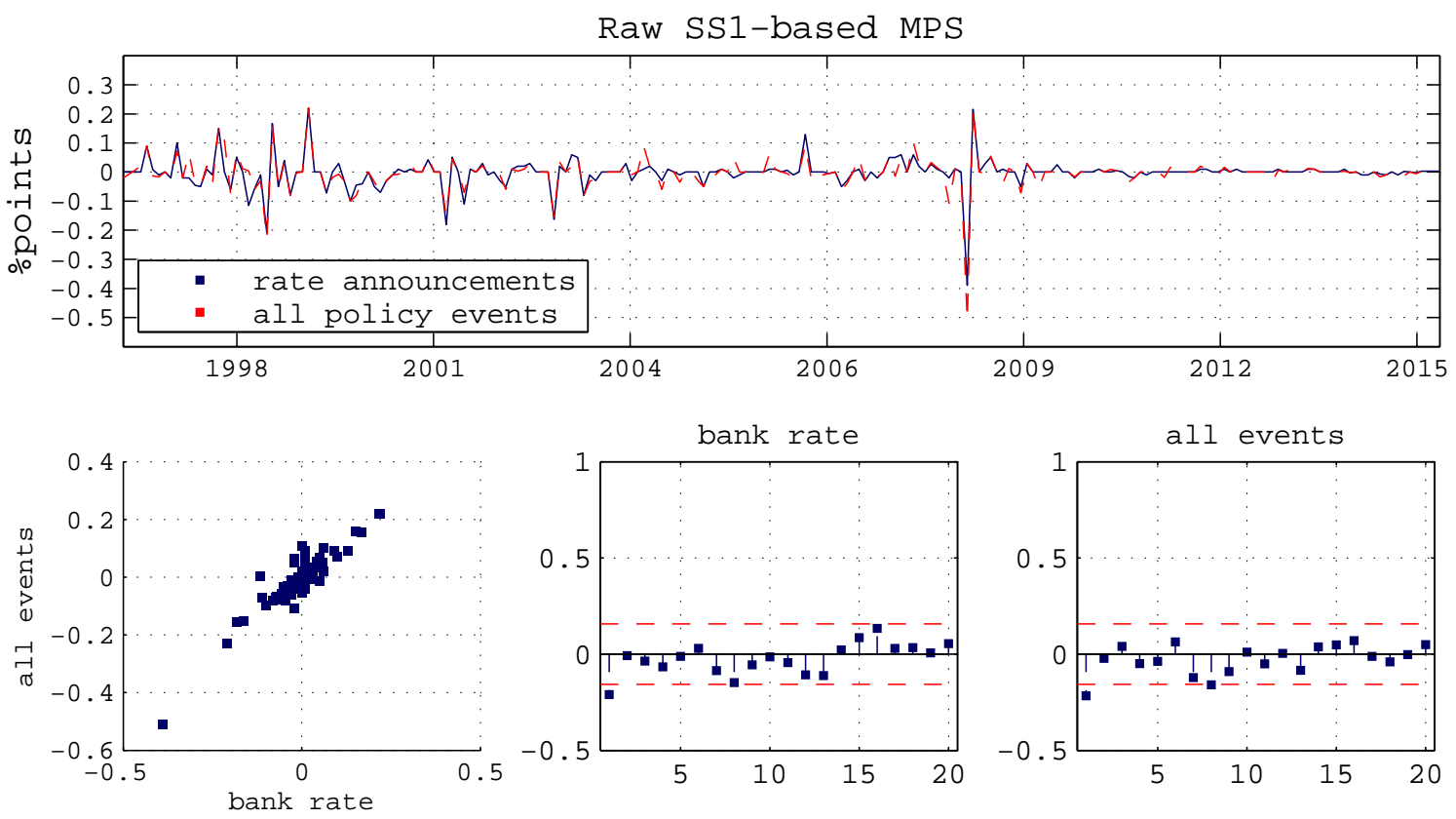

Raw ss1-based monetary surprise at monthly frequency. Surprises are computed around Bank Rate announcements only ( ss1 - blue line) and when also minutes and releases of the Inflation Report are taken into account ( SS1MIR - red dotted line). All surprises control for data releases contemporaneous to the policy events in the sample considered. In the bottom panel, from left to right, the different information content in the two series and their partial autocorrelation functions.

the day of the rate decisions, market participants infer what the MPC's assessment for current and future economic outlook is likely to be, and interpret the policy decision accordingly. Contrary to the US, raw UK-based monthly surprises display some (negative) autocorrelation even if no weighting scheme is adopted in their construction. The presence of autocorrelation in the first lag persists also if the effective lower bound period (post March 2009) is removed from the analysis. 


\section{B Additional Charts}

\section{Figure B.I: RAW AND ORTHOGONAL MONETARY ACROSS SUBSAMPLES - US}
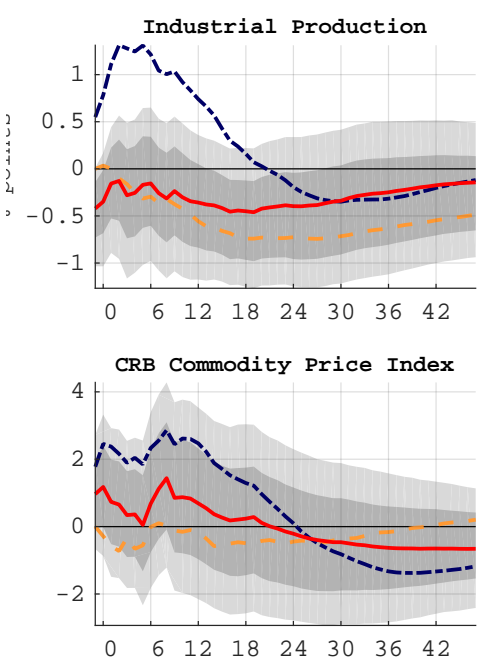

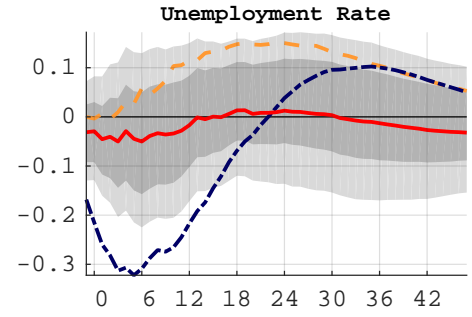

Policy Rate

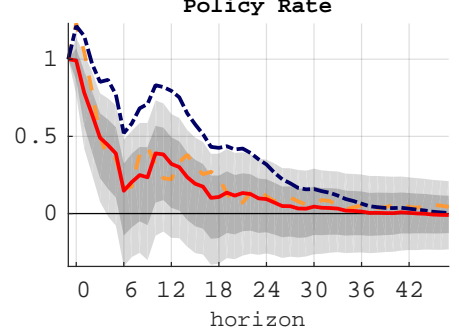

CPI All

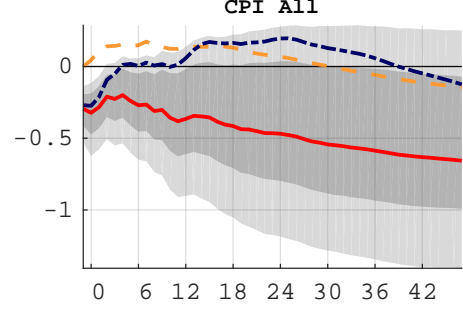

Cholesky

- Raw Market Surprise

- Orthogonal Proxy

(A) US - VAR(12). Estimation sample 1969:1 - 2007:12, identification sample 1990:1 - 2007:12.
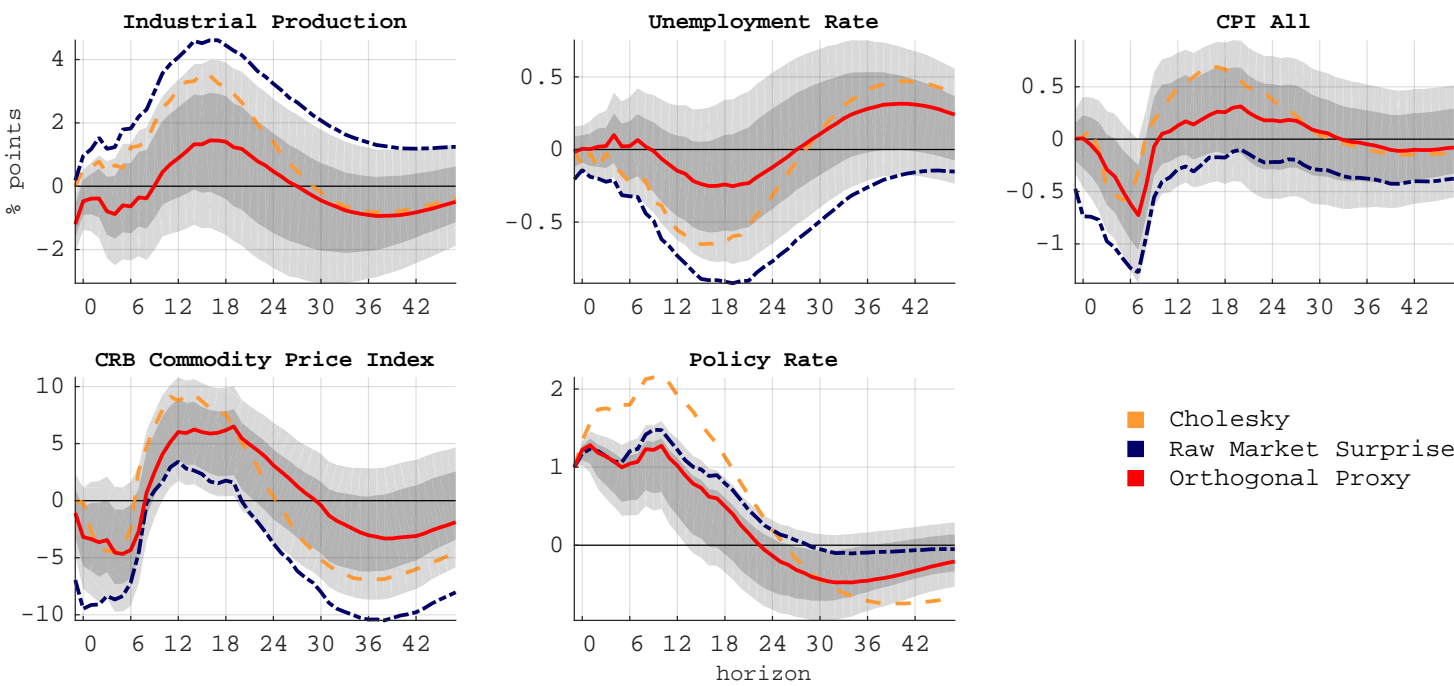

- Cholesky

- Raw Market Surprise

- Orthogonal Proxy

(в) US - VAR(12) Estimation sample 1990:1 - 2012:12, identification sample 1990:1 - 2009:12.

Notes: US - Alternative estimation and identification samples. Recursive identification (yellow dashed) vs identification with external instruments based on the weighted raw FF4 (dark blue dash-dotted) and orthogonal FF $4^{\star}$ monetary surprise (red). $68 \%$ and $90 \%$ bootstrapped confidence bands are obtained with 10,000 replications. IRFs normalized to a $1 \%$ impact increase in the policy rate. 


\section{FigURE B.II: RAW AND ORTHOGONAL SURPRISES ACROSS SUBSAMPLES - UK}
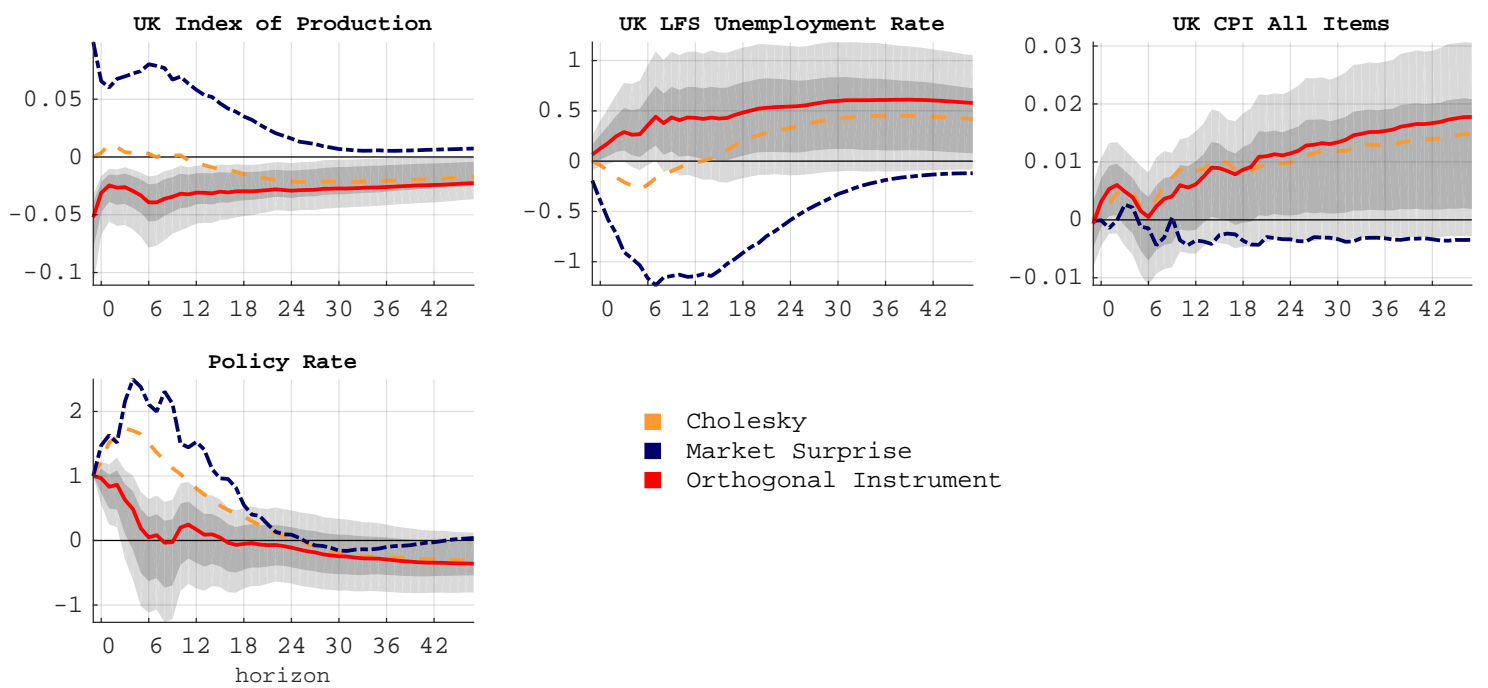

- Cholesky

- Market Surprise

- Orthogonal Instrument

Notes: UK - VAR(12). Estimation sample 1990:1 - 2014:12, identification sample 2001:1 - 2009:12. Recursive identification (yellow dashed) vs identification with external instruments based on the weighted raw Ss1 (dark blue dash-dotted) and orthogonal Ss1* monetary surprise (red). $68 \%$ and 90\% bootstrapped confidence bands are obtained with 10,000 replications. IRFs normalized to a $1 \%$ impact increase in the policy rate.

\section{FIGURE B.III: RAW AND ORTHOGONAL SS1 SURPRISES: BENCHMARK IDENTIFICATION SAMPLE}

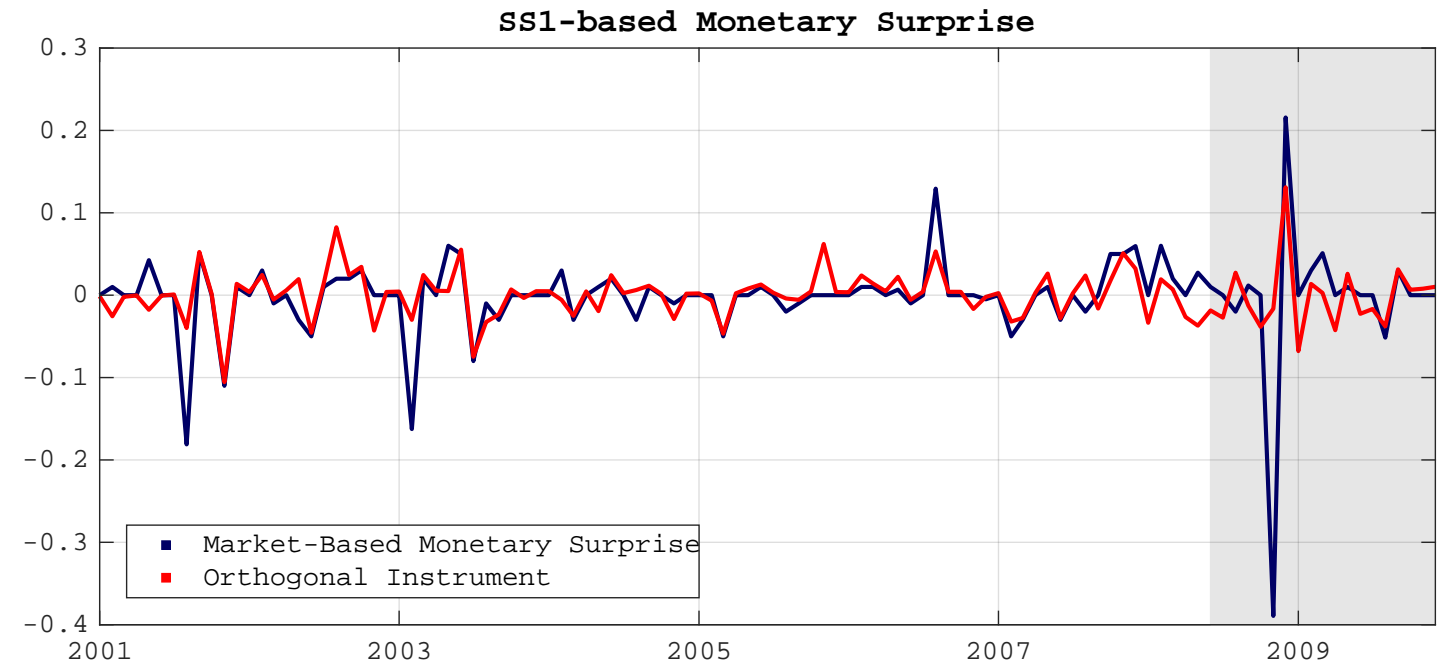

Notes: UK - Benchmark Sample 2001:2009. Raw (Ss1 - blue line) and orthogonal (ss1* - red line) monetary surprises at monthly frequency. Both sets of surprises are extracted from the first short sterling future. Shaded areas denote Economic Cycle Research Institute (ECRI) recessions. 


\section{FIgURE B.IV: RAW AND ORTHOGONAL SURPRISES - EXTENDED IDENTIFICATION SAMPLE - UK}
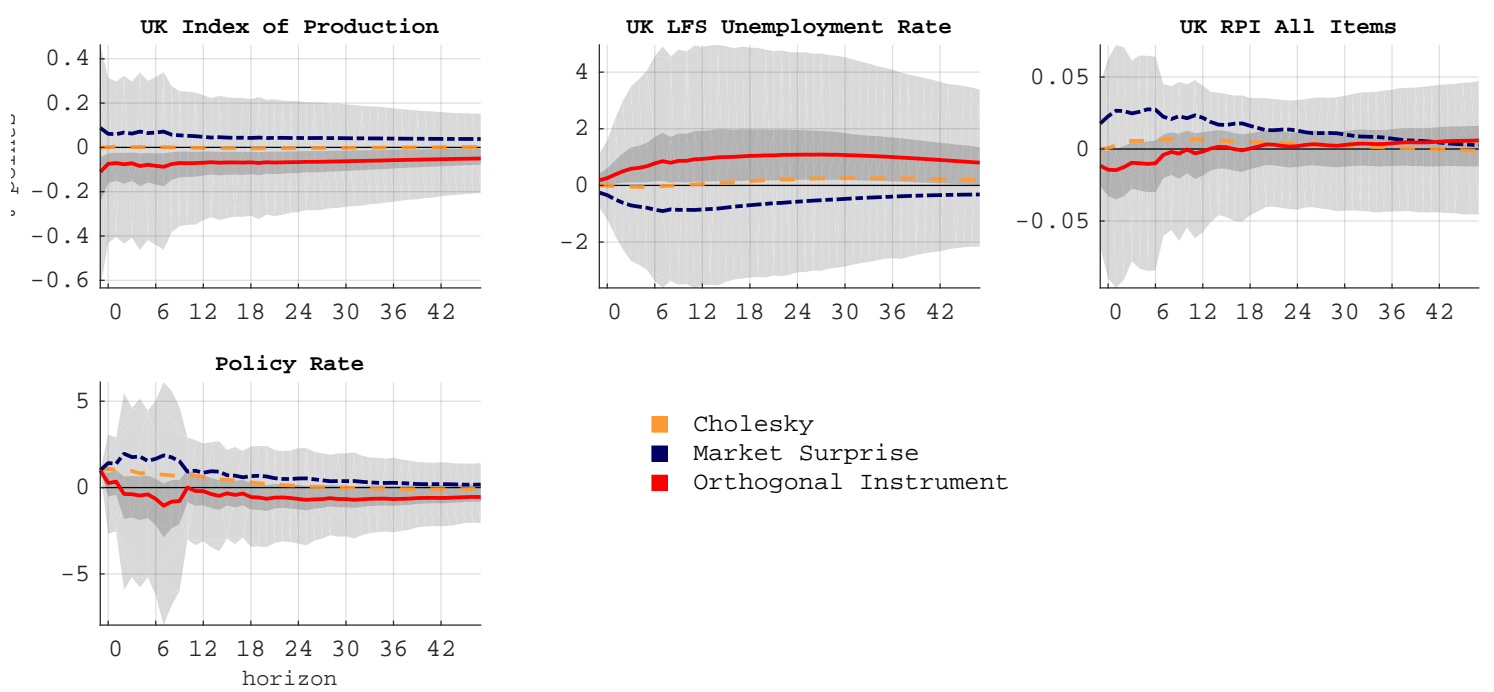

- Cholesky

- Market Surprise

- Orthogonal Instrument

(A) UK - VAR(12). Estimation sample 1979:1 - 2014:12, identification sample 2001:1 - 2015:3.
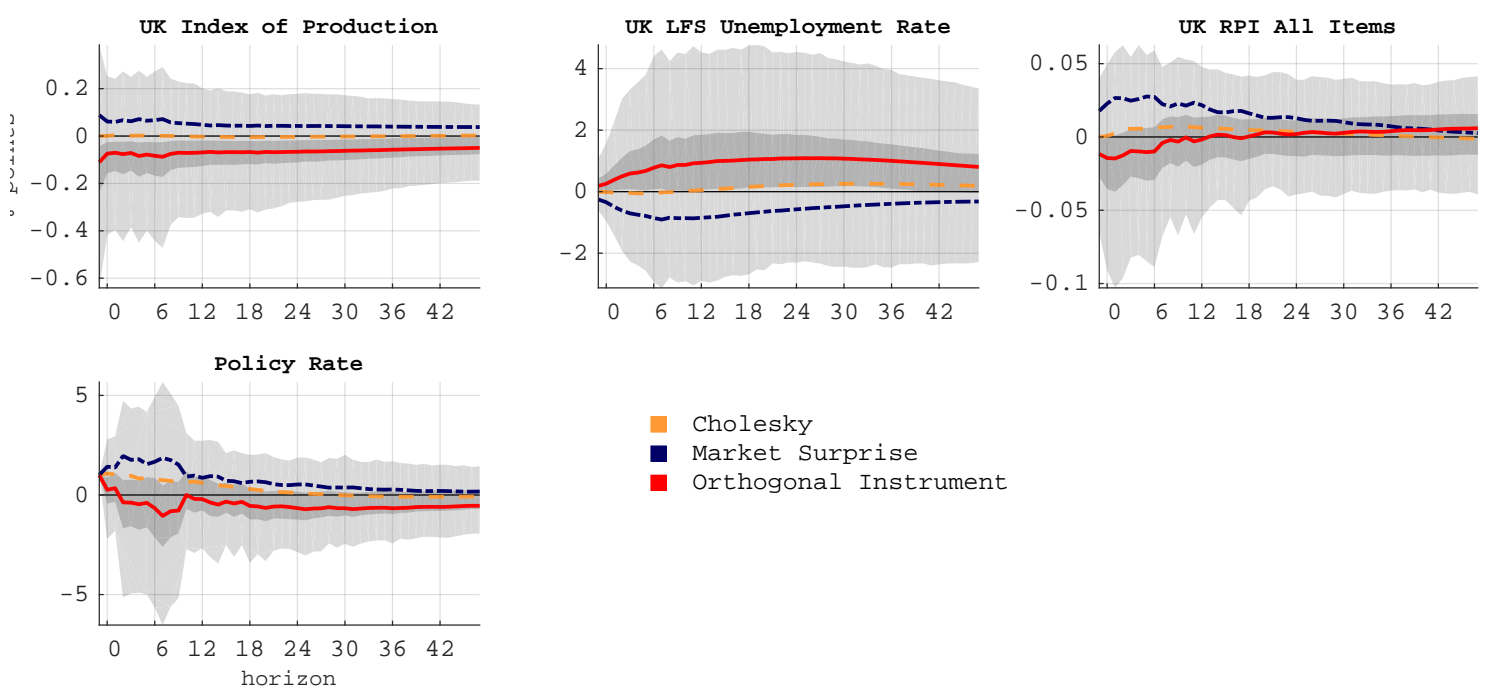

Cholesky

- Market Surprise

- Orthogonal Instrument

(в) UK - VAR(12) Estimation sample 1990:1 - 2014:12, identification sample 1997:7 - 2015:3.

Notes: UK - Alternative identification samples. Recursive identification (yellow dashed) vs identification with external instruments based on the raw Ss1 (dark blue dash-dotted) and orthogonal ss1 ${ }^{\star}$ monetary surprise (red). $68 \%$ and $90 \%$ bootstrapped confidence bands are obtained with 10,000 replications. Shocks are normalized to induce a $1 \%$ increase in the policy rate. 